GLOBAL WATER PATHOGEN PROJECT

PART FOUR. MANAGEMENT OF RISK FROM EXCRETA AND WASTEWATER

\title{
PERSISTENCE OF PATHOGENS IN SEWAGE AND OTHER WATER
} TYPES

Heather Murphy

Temple University

Philadelphia, United States 


\section{Copyright:}

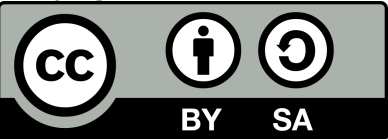

This publication is available in Open Access under the Attribution-ShareAlike 3.0 IGO (CC-BY-SA 3.0 IGO) license (http://creativecommons.org/licenses/by-sa/3.0/igo). By using the content of this publication, the users accept to be bound by the terms of use of the UNESCO Open Access Repository (http://www.unesco.org/openaccess/terms-use-ccbysa-en).

\section{Disclaimer:}

The designations employed and the presentation of material throughout this publication do not imply the expression of any opinion whatsoever on the part of UNESCO concerning the legal status of any country, territory, city or area or of its authorities, or concerning the delimitation of its frontiers or boundaries. The ideas and opinions expressed in this publication are those of the authors; they are not necessarily those of UNESCO and do not commit the Organization.

\section{Citation:}

Murphy, H. (2017). Persistence of Pathogens in Sewage and Other Water Types. In: J.B. Rose and B. Jiménez-Cisneros (eds), Water and Sanitation for the 21st Century: Health and Microbiological Aspects of Excreta and Wastewater Management (Global Water Pathogen Project). (M. Yates (eds), Part 4: Management of Risk from Excreta and Wastewater - Section: Persistence), Michigan State University, E. Lansing, MI, UNESCO. https://doi.org/10.14321/waterpathogens.51

Acknowledgements: K.R.L. Young, Project Design editor; Website Design: Agroknow (http://www.agroknow.com); K. Dean, E. Willis and A. Wissler, reviewed and organized data. 


\section{Summary}

The goal of this chapter is to provide an overview of the literature available on the persistence/ survival of pathogens and indicator organisms in sewage, surface water, groundwater and marine waters. The chapter is based on a scoping review of the literature and includes a summary of the survival of bacteria, viruses, protozoa and indicator organisms under various temperature and light conditions in each of the four water matrices. The data presented herein can be used to understand the survival dynamics of these organisms in aquatic environments and can subsequently be used to inform risk assessment models.

Organism survival/ die-off data are presented and reported as T90, T99, T99.9 or T99.99 values. The T90, T99, T99.9, T99.99 data represent the time in days that it takes for a $1 \log _{10}$ (T90), $2 \log _{10}$ (T99), $3 \log _{10}$ (T99.9) or 4 $\log _{10}$ (T99.00) reduction of the microorganism to be observed.

For example, in sewage, bacterial pathogens such as Salmonella typhimurium, Enterobacter spp. and Streptococcus faecalis can survive for over 100 days before seeing a $1 \log _{10}$ reduction. Adenoviruses in secondary and primary effluent have been found to have T99's of up to 58 and 48 days under dark conditions at cold temperatures $\left(4^{\circ} \mathrm{C}\right)$. These die-off rates decrease as temperature increases as well as when the organisms are exposed to a light source.

Temperature, sunlight, DO, DOC, availability of nutrients, and salinity were found to be important environmental conditions to consider when evaluating the persistence of microorganisms in environmental waters. In general, very few data are available on the persistence of pathogens in aquatic environments, Significant gaps remain, particularly on the persistence of protozoa and pathogens found in developing regions of the world.

\section{Persistence of Pathogens in Sewage and Other Water Types}

\subsection{Introduction}

The goal of this chapter is to provide an overview of the literature available on the persistence/ survival of pathogens and indicator organisms in sewage, surface water, groundwater and marine waters. The chapter includes a summary of the survival of bacteria, viruses, protozoa and indicator organisms under various temperature and light conditions in each of the four water matrices. The data presented herein can be used to understand the survival dynamics of these organisms in aquatic environments and can subsequently be used to inform risk assessment models.

In order to capture a large amount of literature in a short timeframe, a scoping literature review was performed in PubMed from February 11 to 18, 2016 using the search terms described in Table 1 . The search terms within each column in Table 1 were separated by the Boolean search term "OR" and each column of terms were separated by an "AND". The search was restricted to English articles dating back to 1980 that contained the search terms in either the title or abstract. The initial search returned 1216 articles. Abstracts and titles were screened for relevance. Articles that contained information on the persistence or survival of microorganisms in water matrices were retained for data extraction. Data were extracted from a total of 107 relevant articles of which 42 articles contained specific data on the survival/ persistence of specific microorganisms in different water matrices. Only papers where die-off data were presented as log reductions, T90s or could be readily converted to T90s were retained in the review. These data are discussed and presented in the following sections. Three additional references were added to the review that were published after the initial searching took place. Tables 2 to 16 present a summary of the persistence data recovered during the literature review. The survival/ die-off data in the tables are reported as T90, T99, T99.9 or T99.99 values. The T90 and T99 data represent the time in days that it takes for a $1 \log _{10}$ (T90) or $2 \log _{10}$ (T99) reduction of the microorganism to be observed. The T99.9 and T99.99 data represent the time in days that it takes for a $3 \log _{10}$ or $4 \log _{10}$ reduction, respectively. 
Table 1. Search terms

\begin{tabular}{lccc}
\hline & Microorganism Terms & Persistence Terms & Water Matrices Terms \\
\hline Helminths & & \\
Protozoa & & \\
Viruses & & \\
Bacteria & Rotavirus & Wastewater \\
Pathogen & Echovirus & Lagoon \\
Adenovirus & Reovirus & River \\
Enterovirus & Gastroenteritis viruses & Lake \\
E. coli & MST & Persistence & Groundwater \\
Shigella & Genetic markers & Seawater \\
Salmonella & Enterococci & Estuary \\
Campylobacter & Feces OR fecal & Marine \\
MS2 & Indicator(s) & & Decay \\
Cyclospora & Indicators and reagents & & \\
Toxoplasma & & & \\
Cryptosporidium & & & \\
Giardia & & & \\
Norovirus & & & \\
\end{tabular}

\subsection{Persistence in Sewage and Treated Wastewater}

Tables 2 to 4 present a summary of the survival of bacteria, bacteriophages and viruses in wastewater under varying temperatures and light conditions. The data are presented for different types of wastewater including: raw wastewater, primary effluent, secondary effluent, aerated lagoons, wastewater diluted into environmental waters, and wastewater sludge into environmental waters. The survival/ die- off data are reported as T90, T99, T99.9 or T99.99 values. Data were aggregated where possible by temperature range and light source. The studies that looked at persistence in wastewater were performed in the dark, under light or under UVA or UVB radiation.

In the present review, 9 of the 45 articles focused on the survival of indicator organisms or pathogens in wastewater. The majority of the data found in these articles was on the persistence of bacteria (12 types of bacteria) followed by viruses (4 human specific viruses) and then by bacteriophage (2 types of bacteriophages). Bacteriophages are viruses that infect bacteria. No studies were found on the persistence of protozoa in wastewater.

\subsection{Bacteria and bacterial indicators}

Several studies examined the survival of Escherichia coli in untreated wastewater under dark conditions (Table 2 ). It seems to be most persistent at low temperatures ( 2 to $6^{\circ} \mathrm{C}$ ), where it is shown to survive for $>11$ days before seeing a $1 \log _{10}$ reduction. In secondary wastewater effluent, Mayer et al. (2015) found E.coli spp. to be less persistent and observed a $1 \log _{10}$ die-off after 4 to 11 days. Once temperatures rise to above $21^{\circ} \mathrm{C}$, die-off is more rapid and ranged from 1 to 7.1 days to achieve a $1 \log _{10}$ reduction. These observations were consistent with the results from other studies that showed increased die-off of bacteria (thermotolerant coliforms, Enterococci, Bacteroides) in wastewaters when temperatures increase above $18.5^{\circ} \mathrm{C}$ (Table 2). For example, at colder temperatures $\left(5^{\circ} \mathrm{C}\right)$ Brooke et al. (2015) observed a $1 \log _{10}$ die-off of Bacteroides thetaiotaomicron only after 9.6 days, however at temperatures ranging from 25 to $43^{\circ} \mathrm{C}$, T90s of 1 to 1.8 were reported. This was consistent with findings of the persistence of human specific Bacteroides (BacHumUCD; AllBac) in raw wastewater and secondary effluent, where a $1 \log _{10}$ reduction was only observed at $5^{\circ} \mathrm{C}$ after 11 days (Mayer et al. 2015). The same log reduction was observed at 4 days when the temperature was $21^{\circ} \mathrm{C}$, further highlighting the importance of temperature on the survival of some bacteria in wastewater (Mayer et al. 2015). In contrast, Mayer et al. (2015) observed no significant difference in die off of Clostridium perfringens in raw wastewater and secondary effluent at cold $\left(5^{\circ} \mathrm{C}\right)$ and warm $\left(21^{\circ} \mathrm{C}\right)$ temperatures. Yeager and Ward (1981) examined the survival of pathogens in sewage sludge at $21^{\circ} \mathrm{C}$ and found that in liquid sludge ( $5 \%$ solids) the pathogens Salmonella typhimurium, Enterobacter spp. and Streptococcus faecalis and the indicator organism E.coli spp. could survive for greater than 100 days before seeing even a $1 \log _{10}$ die-off. 
Table 2. Summary of the persistence of pathogenic and indicator bacteria in wastewater or sewage under different temperatures conditions

\begin{tabular}{|c|c|c|c|c|c|}
\hline Bacteria Type $^{\text {a }}$ & $\begin{array}{c}\text { T90 } \\
\text { (Days) }\end{array}$ & Temperature $\left({ }^{\circ} \mathrm{C}\right)$ & Light Source & Wastewater Type & References \\
\hline $\begin{array}{l}\text { Bacteroides } \\
\text { thetaiotaomicron }\end{array}$ & 9.6 & 2 to 6 & Dark & $\begin{array}{c}10 \% \text { sewage by } \\
\text { volume into river } \\
\text { water }\end{array}$ & $\begin{array}{l}\text { Brooks et al., } \\
2015\end{array}$ \\
\hline $\begin{array}{l}\text { Bacteroides } \\
\text { thetaiotaomicron }\end{array}$ & 1.8 & 25 to 29 & Dark & $\begin{array}{c}10 \% \text { sewage by } \\
\text { volume into river } \\
\text { water }\end{array}$ & $\begin{array}{l}\text { Brooks et al., } \\
\quad 2015\end{array}$ \\
\hline $\begin{array}{l}\text { Bacteroides } \\
\text { thetaiotaomicron }\end{array}$ & 1 & 32 to 43 & Dark & $\begin{array}{c}10 \% \text { sewage by } \\
\text { volume into river } \\
\text { water }\end{array}$ & $\begin{array}{l}\text { Brooks et al., } \\
2015\end{array}$ \\
\hline $\begin{array}{l}\text { Bifidobacterium } \\
\text { adolescentis }^{\mathrm{b}}\end{array}$ & 3.6 to 3.7 & 18.5 & Dark & $\begin{array}{l}\text { 1:18\% dilution WW } \\
\text { into seawater or } \\
\text { freshwater }\end{array}$ & $\begin{array}{c}\text { Jeanneau et al., } \\
2012\end{array}$ \\
\hline Clostridium perfringens & $>11$ & 5 & Dark & Raw Wastewater & $\begin{array}{l}\text { Mayer et al., } \\
2015\end{array}$ \\
\hline Clostridium perfringens & $>11$ & 5 & Dark & Secondary effluent & $\begin{array}{l}\text { Mayer et al., } \\
2015\end{array}$ \\
\hline Clostridium perfringens & $>11$ & 21 & Dark & Raw Wastewater & $\begin{array}{l}\text { Mayer et al., } \\
2015\end{array}$ \\
\hline Clostridium perfringens & $>11$ & 21 & Dark & Secondary effluent & $\begin{array}{l}\text { Mayer et al., } \\
2015\end{array}$ \\
\hline E.coli spp. & 12.4 & 2 to 6 & Dark & $\begin{array}{c}10 \% \text { sewage by } \\
\text { volume into river } \\
\text { water }\end{array}$ & $\begin{array}{l}\text { Brooks et al., } \\
2015\end{array}$ \\
\hline E.coli spp. & $>11$ & 5 & Dark & Raw Wastewater & $\begin{array}{l}\text { Mayer et al., } \\
2015\end{array}$ \\
\hline E.coli spp. & 4 to 11 & 5 & Dark & Secondary effluent & $\begin{array}{l}\text { Mayer et al., } \\
2015\end{array}$ \\
\hline E.coli spp. & 1.7 to 5.8 & 18.5 & Dark & $\begin{array}{l}\text { 1:18\% dilution WW } \\
\text { into seawater or } \\
\text { freshwater }\end{array}$ & $\begin{array}{c}\text { Jeanneau et al., } \\
2012\end{array}$ \\
\hline E.coli spp. & $>100$ & 21 & $\mathrm{NR}^{\mathrm{c}}$ & $\begin{array}{c}\text { moisture } \\
\text { content }=5 \% \text { solid } \\
\text { sludge }\end{array}$ & $\begin{array}{l}\text { Yeager and } \\
\text { Ward, } 1981\end{array}$ \\
\hline E.coli spp. & 4 & 21 & Dark & Raw Wastewater & $\begin{array}{l}\text { Mayer et al., } \\
2015\end{array}$ \\
\hline E.coli spp. & 1 to 4 & 21 & Dark & Secondary effluent & $\begin{array}{l}\text { Mayer et al., } \\
2015\end{array}$ \\
\hline E.coli spp. & 7.1 & 25 to 29 & Dark & $\begin{array}{c}10 \% \text { sewage by } \\
\text { volume into river } \\
\text { water }\end{array}$ & $\begin{array}{l}\text { Brooks et al., } \\
2015\end{array}$ \\
\hline E.coli spp. & 6 & 32 to 43 & Dark & $\begin{array}{c}10 \% \text { sewage by } \\
\text { volume into river } \\
\text { water }\end{array}$ & $\begin{array}{l}\text { Brooks et al., } \\
2015\end{array}$ \\
\hline Enterobacter spp. & $>100$ & 21 & $\mathrm{NR}^{\mathrm{c}}$ & $\begin{array}{c}\text { moisture } \\
\text { content }=5 \% \text { solid } \\
\text { sludge }\end{array}$ & $\begin{array}{l}\text { Yeager and } \\
\text { Ward, } 1981\end{array}$ \\
\hline Enterococci & $>28$ & 2 to 6 & Dark & $\begin{array}{c}10 \% \text { sewage by } \\
\text { volume into river } \\
\text { water }\end{array}$ & $\begin{array}{l}\text { Brooks et al., } \\
2015\end{array}$ \\
\hline Enterococci & 3.1 to 3.6 & 18.5 & Dark & $\begin{array}{l}\text { 1:18\% dilution WW } \\
\text { into seawater or } \\
\text { freshwater }\end{array}$ & $\begin{array}{c}\text { Jeanneau et al., } \\
2012\end{array}$ \\
\hline Enterococci & 8.4 & 25 to 29 & Dark & $\begin{array}{c}10 \% \text { sewage by } \\
\text { volume into river } \\
\text { water }\end{array}$ & $\begin{array}{l}\text { Brooks et al., } \\
2015\end{array}$ \\
\hline Enterococci & 6.5 & 32 to 43 & Dark & $\begin{array}{c}10 \% \text { sewage by } \\
\text { volume into river } \\
\text { water }\end{array}$ & $\begin{array}{l}\text { Brooks et al., } \\
2015\end{array}$ \\
\hline
\end{tabular}




\begin{tabular}{|c|c|c|c|c|c|}
\hline Bacteria Type $^{a}$ & $\begin{array}{c}\text { T90 } \\
\text { (Days) }\end{array}$ & Temperature $\left({ }^{\circ} \mathrm{C}\right)$ & Light Source & Wastewater Type & References \\
\hline $\begin{array}{l}\text { Human specific } \\
\text { Bacteroides (HF183) }\end{array}$ & 1.7 to 2.3 & 18.5 & Dark & $\begin{array}{l}\text { 1:18\% dilution WW } \\
\text { into seawater or } \\
\text { freshwater }\end{array}$ & $\begin{array}{c}\text { Jeanneau et al., } \\
2012\end{array}$ \\
\hline $\begin{array}{l}\text { Human specific } \\
\text { Bacteroides (BacHum- } \\
\text { UCD) }\end{array}$ & 11 & 5 & Dark & Raw Wastewater & $\begin{array}{l}\text { Mayer et al., } \\
2015\end{array}$ \\
\hline $\begin{array}{l}\text { Human specific } \\
\text { Bacteroides (BacHum- } \\
\text { UCD) }\end{array}$ & $>11$ & 5 & Dark & Secondary effluent & $\begin{array}{l}\text { Mayer et al., } \\
2015\end{array}$ \\
\hline $\begin{array}{l}\text { Human specific } \\
\text { Bacteroides (BacHum- } \\
\text { UCD) }^{b}\end{array}$ & 4 & 21 & Dark & Secondary effluent & $\begin{array}{l}\text { Mayer et al., } \\
2015\end{array}$ \\
\hline $\begin{array}{l}\text { Human Specific } \\
\text { Bacteroides (AllBac) }\end{array}$ & $>11$ & 5 & Dark & Raw Wastewater & $\begin{array}{l}\text { Mayer et al., } \\
2015\end{array}$ \\
\hline $\begin{array}{l}\text { Human Specific } \\
\text { Bacteroides (AllBac) }{ }^{b}\end{array}$ & $>11$ & 5 & Dark & Secondary effluent & $\begin{array}{l}\text { Mayer et al., } \\
2015\end{array}$ \\
\hline $\begin{array}{l}\text { Human Specific } \\
\text { Bacteroides (AllBac) }{ }^{b}\end{array}$ & 4 to 11 & 21 & Dark & Raw Wastewater & $\begin{array}{l}\text { Mayer et al., } \\
2015\end{array}$ \\
\hline $\begin{array}{l}\text { Human Specific } \\
\text { Bacteroides (AllBac) }\end{array}$ & 4 & 21 & Dark & Secondary effluent & $\begin{array}{l}\text { Mayer et al., } \\
2015\end{array}$ \\
\hline Klebsella & 50 to 75 & 21 & $\mathrm{NR}^{\mathrm{c}}$ & $\begin{array}{c}\text { moisture } \\
\text { content }=5 \% \text { solid } \\
\text { sludge }\end{array}$ & $\begin{array}{l}\text { Yeager and } \\
\text { Ward, } 1981\end{array}$ \\
\hline Salmonella Typhimurium & $>100$ & 21 & $\mathrm{NR}^{\mathrm{c}}$ & $\begin{array}{c}\text { moisture } \\
\text { content }=5 \% \text { solid } \\
\text { sludge }\end{array}$ & $\begin{array}{l}\text { Yeager and } \\
\text { Ward, } 1981\end{array}$ \\
\hline Streptococcus faecalis & $>100$ & 21 & $\mathrm{NR}^{\mathrm{c}}$ & $\begin{array}{c}\text { moisture } \\
\text { content }=5 \% \text { solid } \\
\text { sludge }\end{array}$ & $\begin{array}{l}\text { Yeager and } \\
\text { Ward, } 1981\end{array}$ \\
\hline
\end{tabular}

${ }^{a}$ Unless specified otherwise, all data presented are from cultured organisms and were not monitored using molecular methods; ${ }^{b}$ Detected/ monitored using molecular methods; ${ }^{c}$ NR: Not Reported

\subsection{Viruses and viral indicators}

In a variety of wastewaters including: raw sewage, primary effluent, secondary effluent, and aerated lagoons, temperature influenced the survival of bacteriophages and viruses. In experiments by Carratalà et al. (2013), Enriquez (1994), and Skraber et al. (2009), viral persistence and bacteriophage survival consistently decreased at temperatures above $15^{\circ} \mathrm{C}$ compared to $4^{\circ} \mathrm{C}$ (Tables 3 and
4). Carratalà et al. (2013) found that adenoviruses were susceptible to UVB radiation at $7^{\circ} \mathrm{C}$ and that UVA radiation had a larger effect on the persistence of adenovirus at $37^{\circ} \mathrm{C}$ than $20^{\circ} \mathrm{C}$ (Table 4). There were no direct comparison experiment of UVA and UVB radiation at the same temperature conditions, therefore it is difficult to compare the UVA and UVB results. Nevertheless, the studies found suggest that UV radiation and temperature are important factors for the persistence of pathogens in different wastewater matrices, particularly in cold environments. 
Table 3. Summary of the persistence of bacteriophage in wastewater or sewage under different temperature and light conditions

\begin{tabular}{|c|c|c|c|c|c|}
\hline $\begin{array}{c}\text { Bacteriophage } \\
\text { Typ }^{\mathrm{a}}\end{array}$ & $\begin{array}{c}\text { T90 } \\
\text { (Days) }\end{array}$ & $\begin{array}{c}\text { Temperature } \\
\left({ }^{\circ} \mathrm{C}\right)\end{array}$ & Light Source & Wastewater Type & References \\
\hline $\begin{array}{l}\text { F specific RNA } \\
\text { phage }^{b}\end{array}$ & 1.1 to 5.2 & 18.5 & Dark & $\begin{array}{l}\text { 1:18\% dilition WW } \\
\text { into sewater or } \\
\text { freshwater }\end{array}$ & $\begin{array}{l}\text { Jeanneau et al., } \\
2012\end{array}$ \\
\hline $\begin{array}{l}\text { Infectious F specific } \\
\text { phage }\end{array}$ & 8.8 & 4 & Dark & Primary effluent & Skraber et al., 2009 \\
\hline $\begin{array}{l}\text { Infectious F specific } \\
\text { phage }\end{array}$ & $<2.4$ & 20 & Dark & Primary effluent & Skraber et al., 2009 \\
\hline $\begin{array}{l}\text { Phages F specific- } \\
\text { GIII genome }\end{array}$ & 21.2 & 4 & Dark & Primary effluent & Skraber et al., 2009 \\
\hline $\begin{array}{l}\text { Phages F specific- } \\
\text { GIII genome }\end{array}$ & 7.2 & 20 & Dark & Primary effluent & Skraber et al., 2009 \\
\hline
\end{tabular}

${ }^{a}$ Unless specified otherwise, all data presented are from cultured organisms and were not monitored using molecular

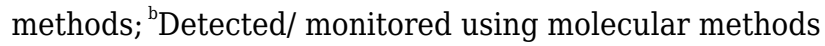


Table 4. Summary of the persistence of viruses in wastewater or sewage under different temperature and light conditions

\begin{tabular}{|c|c|c|c|c|c|c|c|c|}
\hline Virus Type $^{a}$ & $\begin{array}{c}\text { T90 } \\
\text { (Days) }\end{array}$ & $\begin{array}{c}\text { T99 } \\
\text { (Days) }\end{array}$ & $\begin{array}{l}\text { T99.9 } \\
\text { (Days) }\end{array}$ & $\begin{array}{l}\text { T99.99 } \\
\text { (Days) }\end{array}$ & $\begin{array}{c}\text { Temperat } \\
\left({ }^{\mathbf{0}} \mathrm{C}\right)\end{array}$ & Lre & Wastewater Type & References \\
\hline Adenovirus 40 & NR & RU & NR & NR & 4 & Dark & Secondary effluent & Enriquez et al., 1994 \\
\hline Adenovirus 40 & NR & $4 \mathrm{P}$ & NR & NR & NR & Dark & Secondary effluent & Enriquez et al., 1994 \\
\hline Adenovirus 40 & NR & 44 & NR & NR & 4 & Dark & Primary effluent & Enriquez et al., 1994 \\
\hline Adenovirus 40 & NR & 40 & NR & NR & NR & Dark & Primary effluent & Enriquez et al., 1994 \\
\hline Adenovirus 41 & NR & $4 \mathrm{~T}$ & NR & NR & 4 & Dark & Secondary effluent & Enriquez et al., 1994 \\
\hline Adenovirus 41 & NR & $4 \mathrm{R}$ & NR & NR & NR & Dark & Secondary effluent & Enriquez et al., 1994 \\
\hline Adenovirus 41 & NR & $4 U$ & NR & NR & 4 & Dark & Primary effluent & Enriquez et al., 1994 \\
\hline Adenovirus 41 & NR & $4 \mathrm{P}$ & NR & NR & NR & Dark & Primary effluent & Enriquez et al., 1994 \\
\hline $\begin{array}{l}\text { Human } \\
\text { Adenovirus- type } \\
2\end{array}$ & 0.04 & $0.0 \mathrm{U}$ & $0 . \mathrm{N} 4$ & $0.2 \mathrm{P}$ & $\mathrm{T}$ & UVB Radiation & Raw wastewater & Carratalà et al., 2013 \\
\hline $\begin{array}{l}\text { Human } \\
\text { Adenovirus- type } \\
2\end{array}$ & e 2.50 & R.4P & $\mathrm{U} .2 \mathrm{~S}$ & NN.NO & 20 & rsA oadiation & Raw wastewater & Carratalà et al., 2013 \\
\hline $\begin{array}{l}\text { Human } \\
\text { Adenovirus- type } \\
2\end{array}$ & 0.13 & 0.31 & 0.48 & 0.66 & 37 & Dark & Raw wastewater & Carratalà et al., 2013 \\
\hline $\begin{array}{l}\text { Human } \\
\text { Adenovirus- type } \\
2\end{array}$ & 0.12 & 0.31 & 0.49 & 0.69 & 37 & UVA Radiation & Raw wastewater & Carratalà et al., 2013 \\
\hline $\begin{array}{l}\text { Norovirus GG1 } \\
\text { genome }^{\mathrm{C}}\end{array}$ & 114.9 & NR & NR & NR & 4 & Dark & Primary effluent & Skraber et al., 2009 \\
\hline $\begin{array}{l}\text { Norovirus GG1 } \\
\text { genome }^{\mathrm{C}}\end{array}$ & 22.5 & NR & NR & NR & 20 & Dark & Primary effluent & Skraber et al., 2009 \\
\hline Poliovirus & NR & 49 & NR & NR & 4 & Dark & Secondary effluent & Enriquez et al., 1994 \\
\hline Poliovirus & NR & 19 & NR & NR & 15 & Dark & Secondary effluent & Enriquez et al., 1994 \\
\hline Poliovirus & NR & 36 & NR & NR & 4 & Dark & Primary effluent & Enriquez et al., 1994 \\
\hline Poliovirus & NR & 28 & NR & NR & 15 & Dark & Primary effluent & Enriquez et al., 1994 \\
\hline
\end{tabular}

a'Unless specified otherwise, all data presented are from cultured organisms and were not monitored using molecular

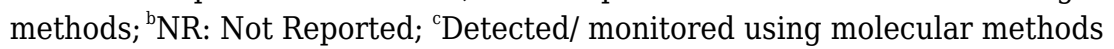

\subsection{Persistence in Surface Waters}

Tables 5, 6, 7, and 8 summarized the findings of the persistence of microorganisms in surface water under varying temperatures and light sources. Survival/ die-off data are reported as T90, T99, T99.9 or T99.99 values. For surface water, all experiments were performed in the dark, under artificial light and under natural sunlight. A couple of studies reported using UVA and UVB radiation specifically.
In the present review, 21 of the 45 articles focused on the survival of indicator organisms or pathogens in surface water supplies. The majority of the data found in these articles were on the persistence of bacteria and bacteriophages in surface water (13 types of bacteriophages; 10 bacteria), followed by viruses ( 6 virus types). Similar to the groundwater, only 1 article presented data on the persistence of protozoa. 


\subsection{Bacteria and bacterial indicators}

In general, bacteria seem to persist for shorter periods of time (T99s ranging from 1.5 to 69.5 days) in surface waters (Table 5 ) than in groundwater (T99s ranging from 2.85 to 119 days) (Table 9). Temperature appears to have a moderate effect on bacterial persistence of indicator organisms such as E. coli spp., fecal coliforms, and fecal enterococci. For example, at temperatures ranging from 13 to $30^{\circ} \mathrm{C}$, T90s for fecal coliforms ranged from between 3.6 to 3.9 days. For fecal enterococci, T90s ranged from 1 to 1.9 days for temperatures between 5 to $17^{\circ} \mathrm{C}$. Interestingly, once temperatures rise to above $22^{\circ} \mathrm{C}$, Balleste and Blanch (2010) reported T90s as high as 4.42 to 5.25 days for fecal enteroccoci. In contrast, persistence of $E$. coli spp. in wastewater seems to be longer at temperatures around $15^{\circ} \mathrm{C}$ (T99: 3.01 to 5.65 ) compared to $25^{\circ} \mathrm{C}$ (T99: 2.18) (Table 3).

Table 5. Summary of the persistence of pathogenic and indicator bacteria in surface waters under different temperature and light conditions

\begin{tabular}{|c|c|c|c|c|c|c|}
\hline Bacteria Type $^{\text {a }}$ & $\begin{array}{c}\text { T90 } \\
\text { (Days) }\end{array}$ & $\begin{array}{c}\text { T99 } \\
\text { (Days) }\end{array}$ & $\begin{array}{c}\text { Temperature } \\
\left({ }^{\circ} \mathrm{C}\right)\end{array}$ & Light Source & Comments & References \\
\hline $\begin{array}{l}\text { Animal Specific } \\
\text { Bacteroides CF193 } \\
\text { DNA }^{\text {c }}\end{array}$ & $\mathrm{NR}^{\mathrm{b}}$ & 2.75 & 15 & Sunlight & NR & Liang et al., 2012 \\
\hline $\begin{array}{l}\text { Animal Specific } \\
\text { Bacteroides CF193 } \\
\text { RNA }^{\mathrm{C}}\end{array}$ & NR & 2.12 & 15 & Sunlight & NR & Liang et al., 2012 \\
\hline Bacteroides spp. ${ }^{\mathrm{d}}$ & 1.27 to 1.77 & NR & 5 to 10 & Sunlight & NR & $\begin{array}{l}\text { Balleste and } \\
\text { Blanch, } 2010\end{array}$ \\
\hline Bacteroides spp. ${ }^{\mathrm{d}}$ & 1.15 & NR & 13 to 15 & Sunlight & NR & $\begin{array}{l}\text { Balleste and } \\
\text { Blanch, } 2010\end{array}$ \\
\hline Bacteroides spp. ${ }^{\mathrm{d}}$ & 0.83 to 0.92 & 2.55 & 22 to 30 & Sunlight & NR & $\begin{array}{c}\text { Balleste and } \\
\text { Blanch, 2010; Dick } \\
\text { et al., } 2010\end{array}$ \\
\hline Bacteroides spp. ${ }^{\mathrm{d}}$ & NR & 2.73 & 15 & Dark & $\begin{array}{l}1 \% \text { WW into } \\
\text { freshwater }\end{array}$ & Dick et al., 2010 \\
\hline Bacteroides spp. ${ }^{\mathrm{d}}$ & NR & 3.28 to 4.44 & 25 & Dark & NR & Dick et al., 2010 \\
\hline $\begin{array}{l}\text { Bacteroides } \\
\text { thetaiotaomicron }^{\mathrm{d}}\end{array}$ & 0.32 to 0.84 & NR & 5 to 10 & Sunlight & NR & $\begin{array}{l}\text { Balleste and } \\
\text { Blanch, } 2010\end{array}$ \\
\hline $\begin{array}{l}\text { Bacteroides } \\
\text { thetaiotaomicron }^{\mathrm{d}}\end{array}$ & 0.65 to 2.91 & NR & 13 to 15 & Sunlight & NR & $\begin{array}{l}\text { Balleste and } \\
\text { Blanch, } 2010\end{array}$ \\
\hline $\begin{array}{l}\text { Bacteroides } \\
\text { thetaiotaomicron }^{\mathrm{d}}\end{array}$ & 0.75 to 2.2 & NR & 22 to 30 & Sunlight & NR & $\begin{array}{l}\text { Balleste and } \\
\text { Blanch, } 2010\end{array}$ \\
\hline Bacteroides fragilis ${ }^{\mathrm{d}}$ & 1 to 8.2 & NR & 5 to 10 & Sunlight & $\begin{array}{c}\text { River water } \& \\
\text { sterile river water }\end{array}$ & $\begin{array}{l}\text { Balleste and } \\
\text { Blanch, } 2010\end{array}$ \\
\hline Bacteroides fragilis ${ }^{\mathrm{d}}$ & 0.82 to 5.41 & NR & 13 to 15 & Sunlight & $\begin{array}{c}\text { River water } \& \\
\text { sterile river water }\end{array}$ & $\begin{array}{l}\text { Balleste and } \\
\text { Blanch, } 2010\end{array}$ \\
\hline Bacteroides fragilis ${ }^{\mathrm{d}}$ & 0.48 to 2.2 & NR & 22 to 30 & Sunlight & $\begin{array}{c}\text { River water } \& \\
\text { sterile river water }\end{array}$ & $\begin{array}{l}\text { Balleste and } \\
\text { Blanch, } 2010\end{array}$ \\
\hline $\begin{array}{l}\text { Bacteroidales pig } 1 \\
\text { bac }^{c}\end{array}$ & 22 & NR & 4 & Dark & NR & Marti et al., 2011 \\
\hline $\begin{array}{l}\text { Bacteroidales pig } 1 \\
\text { bac }^{c}\end{array}$ & 10.3 & NR & 20 & Dark & NR & Marti et al., 2011 \\
\hline $\begin{array}{l}\text { Bacteroidales pig } 2 \\
\text { bac }^{c}\end{array}$ & 19.3 & NR & 4 & Dark & NR & Marti et al., 2011 \\
\hline $\begin{array}{l}\text { Bacteroidales pig } 2 \\
\text { bac }^{c}\end{array}$ & 1.9 & NR & 20 & Dark & NR & Marti et al., 2011 \\
\hline Bovine E.coli & NR & 8.32 & 15 & Nat. light cycle & $\begin{array}{l}\text { bovine feces into } \\
\text { freshwater }\end{array}$ & Liang et al., 2012 \\
\hline Campylobacter & 4.08 & NR & 4 & Dark & NR & $\begin{array}{l}\text { Rodríguez and } \\
\text { Araujo, } 2012\end{array}$ \\
\hline Campylobacter & 2.0 to 7.0 & NR & 10 to 11 & Dark & NR & $\begin{array}{c}\text { Rodríguez and } \\
\text { Araujo, 2012; } \\
\text { Schang et al. } 2016\end{array}$ \\
\hline Campylobacter & 2.3 to 3.8 & 6.3 to 8.7 & 10 to 15 & Nat. Light cycle & $\begin{array}{c}50 \text { to } 100 \mathrm{NTU} \text {, in } \\
\text { stormwater } \\
\text { wetland }\end{array}$ & Meng et al. 2016 \\
\hline Campylobacter & 0.91 to 1.65 & NR & 20 & Dark & NR & $\begin{array}{l}\text { Rodríguez and } \\
\text { Araujo, } 2012\end{array}$ \\
\hline
\end{tabular}




\begin{tabular}{|c|c|c|c|c|c|c|}
\hline Bacteria Type $^{a}$ & $\begin{array}{c}\text { T90 } \\
\text { (Days) }\end{array}$ & $\begin{array}{c}\text { T99 } \\
\text { (Days) }\end{array}$ & $\begin{array}{c}\text { Temperature } \\
\left({ }^{\circ} \mathrm{C}\right)\end{array}$ & Light Source & Comments & References \\
\hline Campylobacter & 0.92 & NR & 30 & Dark & NR & $\begin{array}{l}\text { Rodríguez and } \\
\text { Araujo, } 2012\end{array}$ \\
\hline Campylobacter & 0.46 & NR & 37 & Dark & NR & $\begin{array}{l}\text { Rodríguez and } \\
\text { Araujo, } 2012\end{array}$ \\
\hline Campylobacter & 0.77 & NR & 6.8 & Sunlight & NR & $\begin{array}{l}\text { Rodríguez and } \\
\text { Araujo, } 2012\end{array}$ \\
\hline Campylobacter & 0.692 & NR & 14.1 & Sunlight & NR & $\begin{array}{c}\text { Rodríguez and } \\
\text { Araujo, } 2012\end{array}$ \\
\hline Campylobacter & 0.429 & NR & 22.3 & Sunlight & NR & $\begin{array}{l}\text { Rodríguez and } \\
\text { Araujo, } 2012\end{array}$ \\
\hline Campylobacter & 2.54 & NR & 7.4 & Shade & NR & $\begin{array}{l}\text { Rodríguez and } \\
\text { Araujo, } 2012\end{array}$ \\
\hline Campylobacter & 0.9 & NR & 21.5 & Shade & NR & $\begin{array}{l}\text { Rodríguez and } \\
\text { Araujo, } 2012\end{array}$ \\
\hline $\begin{array}{l}\text { Enterola- } \\
\text { Enteroccoccal 23S } \\
\text { rRNA gene }^{c}\end{array}$ & $>3$ to $<5$ & NR & 14 to 15 & Sunlight & $\begin{array}{c}\text { River water } \& \\
\text { primary effluent } \\
\text { (1:1 ratio) }\end{array}$ & $\begin{array}{c}\text { Korajkic et al. } \\
2014\end{array}$ \\
\hline $\begin{array}{l}\text { Enterola- } \\
\text { Enteroccoccal 23S } \\
\text { rRNA gene }^{c}\end{array}$ & $>3$ to $<5$ & NR & 14 to 15 & Sunlight ${ }^{\mathrm{e}}$ & $\begin{array}{l}\text { River water } \& \\
\text { primary effluent } \\
\text { (1:1 ratio) }\end{array}$ & $\begin{array}{c}\text { Korajkic et al. } \\
2014\end{array}$ \\
\hline $\begin{array}{l}\text { Enterola- } \\
\text { Enteroccoccal 23S } \\
\text { rRNA gene }^{c}\end{array}$ & $>3$ to $<5$ & NR & 14 to 15 & Dark & $\begin{array}{c}\text { River water } \& \\
\text { primary effluent } \\
\text { (1:1 ratio) }\end{array}$ & $\begin{array}{c}\text { Korajkic et al. } \\
2014\end{array}$ \\
\hline $\begin{array}{l}\text { Enterola- } \\
\text { Enteroccoccal 23S } \\
\text { rRNA gene }^{c}\end{array}$ & $>3$ to $<5$ & NR & 14 to 15 & $\operatorname{Dark}^{\mathrm{e}}$ & $\begin{array}{c}\text { River water } \& \\
\text { primary effluent } \\
\text { (1:1 ratio })\end{array}$ & $\begin{array}{c}\text { Korajkic et al. } \\
2014\end{array}$ \\
\hline Enterococci & $<3$ & NR & 14 to 15 & Sunlight & $\begin{array}{c}\text { River water \& } \\
\text { primary effluent } \\
\text { (1:1 ratio) }\end{array}$ & $\begin{array}{c}\text { Korajkic et al. } \\
2014\end{array}$ \\
\hline Enterococci & $<3$ & NR & 14 to 15 & Sunlight $\mathrm{e}^{\mathrm{e}}$ & $\begin{array}{c}\text { River water } \& \\
\text { primary effluent } \\
\text { (1:1 ratio) }\end{array}$ & $\begin{array}{c}\text { Korajkic et al. } \\
2014\end{array}$ \\
\hline Enterococci & $<3$ & NR & 14 to 15 & Dark & $\begin{array}{l}\text { River water \& } \\
\text { primary effluent } \\
\text { (1:1 ratio) }\end{array}$ & $\begin{array}{c}\text { Korajkic et al. } \\
2014\end{array}$ \\
\hline Enterococci & $<5$ & NR & 14 to 15 & $\operatorname{Dark}^{\mathrm{e}}$ & $\begin{array}{c}\text { River water \& } \\
\text { primary effluent } \\
\text { (1:1 ratio) }\end{array}$ & $\begin{array}{l}\text { Korajkic et al. } \\
2014\end{array}$ \\
\hline $\begin{array}{l}\text { Enterotoxigenic } E \text {. } \\
\text { coli }\end{array}$ & NR & 69.5 & 21 & Nat. light cycle & NR & $\begin{array}{l}\text { Lothigius et al., } \\
2010\end{array}$ \\
\hline E.coli O157:H7 & NR & 2.8 to 10.6 & 10 & Dark & River & Avery et al., 2008 \\
\hline E.coli O157:H7 & NR & 9 to 19.4 & 10 & Dark & Lake & Avery et al., 2008 \\
\hline E. coli spp. & NR & $>43$ & 4 & Dark & NR & Marti et al., 2011 \\
\hline E. coli spp. & 2.2 & 3.01 to 5.65 & 15 & Sunlight & NR & $\begin{array}{l}\text { Ahmed et al. 2014; } \\
\text { Dick et al., 2010; } \\
\text { Liang et al., 2012 }\end{array}$ \\
\hline E. coli spp. & 7.2 to 14.7 & 15.5 to 29.6 & 10 to 15 & Nat. Light cycle & $\begin{array}{l}50 \text { to } 100 \mathrm{NTU} \text {, in } \\
\text { stormwater } \\
\text { wetland }\end{array}$ & Meng et al. 2016 \\
\hline E. coli spp. & $<7$ & & 20 to 30 & Nat. light cycle & NR & Schang et al. 2016 \\
\hline E. coli spp. & NR & 2.02 & 25 & Dark & NR & Dick et al., 2010 \\
\hline E. coli spp. & NR & 2.18 & 25 & Sunlight & NR & Dick et al., 2010 \\
\hline E. coli spp. & $>3$ to $<5$ & NR & 14 to 15 & Sunlight & $\begin{array}{c}\text { River water \& } \\
\text { primary effluent } \\
\text { (1:1 ratio) }\end{array}$ & $\begin{array}{c}\text { Korajkic et al. } \\
2014\end{array}$ \\
\hline E. coli spp. & $>3$ to $<5$ & NR & 14 to 15 & Sunlight ${ }^{\mathrm{d}}$ & $\begin{array}{l}\text { River water } \& \\
\text { primary effluent } \\
\text { (1:1 ratio) }\end{array}$ & $\begin{array}{c}\text { Korajkic et al. } \\
2014\end{array}$ \\
\hline E. coli spp. & $<5$ & NR & 14 to 15 & Dark & $\begin{array}{c}\text { River water \& } \\
\text { primary effluent } \\
\text { (1:1 ratio) }\end{array}$ & $\begin{array}{c}\text { Korajkic et al. } \\
2014\end{array}$ \\
\hline E. coli spp. & $<5$ & NR & 14 to 15 & $\operatorname{Dark}^{\mathrm{e}}$ & $\begin{array}{l}\text { River water } \& \\
\text { primary effluent } \\
\text { (1:1 ratio) }\end{array}$ & $\begin{array}{c}\text { Korajkic et al. } \\
2014\end{array}$ \\
\hline Fecal Coliforms & 4.6 to 5.2 & NR & 5 to 10 & Sunlight & NR & $\begin{array}{c}\text { Balleste and } \\
\text { Blanch, } 2010\end{array}$ \\
\hline
\end{tabular}




\begin{tabular}{|c|c|c|c|c|c|c|}
\hline Bacteria Type $^{\mathrm{a}}$ & $\begin{array}{c}\text { T90 } \\
\text { (Days) }\end{array}$ & $\begin{array}{c}\text { T99 } \\
\text { (Days) }\end{array}$ & $\begin{array}{c}\text { Temperature } \\
\left({ }^{\circ} \mathrm{C}\right) \\
\end{array}$ & Light Source & Comments & References \\
\hline Fecal Coliforms & 3.9 & NR & 13 to 15 & Sunlight & NR & $\begin{array}{c}\text { Balleste and } \\
\text { Blanch, } 2010\end{array}$ \\
\hline Fecal Coliforms & 3.6 to 3.7 & NR & 22 to 30 & Sunlight & NR & $\begin{array}{c}\text { Balleste and } \\
\text { Blanch, } 2010\end{array}$ \\
\hline Fecal Enteroccocci & $>43$ & NR & 4 & Dark & NR & Marti et al., 2011 \\
\hline Fecal Enteroccocci & 1 to 1.25 & NR & 5 to 10 & Sunlight & NR & $\begin{array}{c}\text { Balleste and } \\
\text { Blanch, } 2010\end{array}$ \\
\hline Fecal Enteroccocci & 2.3 & NR & 13 to 15 & Sunlight & NR & $\begin{array}{c}\text { Balleste and } \\
\text { Blanch, } 2010\end{array}$ \\
\hline Fecal Enteroccocci & 1.9 & NR & 14 to 17 & Sunlight & NR & Ahmed et al. 2014 \\
\hline Fecal Enteroccocci & 4.42 to 5.25 & NR & 22 to 30 & Sunlight & NR & $\begin{array}{c}\text { Balleste and } \\
\text { Blanch, } 2010\end{array}$ \\
\hline $\begin{array}{l}\text { GenBac3 } \\
\text { Bacteroidales 16s } \\
\text { RNA gene }^{c}\end{array}$ & $>3$ to $<5$ & NR & 14 to 15 & Sunlight & $\begin{array}{c}\text { River water } \& \\
\text { primary effluent } \\
\text { (1:1 ratio) }\end{array}$ & $\begin{array}{c}\text { Korajkic et al. } \\
2014\end{array}$ \\
\hline $\begin{array}{l}\text { GenBac3 } \\
\text { Bacteroidales 16s } \\
\text { RNA gene }^{\mathrm{c}}\end{array}$ & $>3$ to $<5$ & NR & 14 to 15 & Sunlight & $\begin{array}{c}\text { River water } \& \\
\text { primary effluent } \\
\text { (1:1 ratio) }\end{array}$ & $\begin{array}{c}\text { Korajkic et al. } \\
2014\end{array}$ \\
\hline $\begin{array}{l}\text { GenBac3 } \\
\text { Bacteroidales 16s } \\
\text { RNA gene }^{\mathrm{c}}\end{array}$ & $>3$ to $<5$ & NR & 14 to 15 & Dark & $\begin{array}{l}\text { River water } \& \\
\text { primary effluent } \\
\text { (1:1 ratio) }\end{array}$ & $\begin{array}{c}\text { Korajkic et al. } \\
2014\end{array}$ \\
\hline $\begin{array}{l}\text { GenBac3 } \\
\text { Bacteroidales 16s } \\
\text { RNA gene }^{c}\end{array}$ & $>3$ to $<5$ & NR & 14 to 15 & Dark & $\begin{array}{c}\text { River water \& } \\
\text { primary effluent } \\
\text { (1:1 ratio) }\end{array}$ & $\begin{array}{c}\text { Korajkic et al. } \\
2014\end{array}$ \\
\hline Human E. coli & NR & 5.65 & 16 & Nat. light cycle & $\begin{array}{l}\text { human feces into } \\
\text { freshwater }\end{array}$ & Liang et al., 2012 \\
\hline $\begin{array}{l}\text { Human Specific } \\
\text { Bacteroides HF183 } \\
\text { DNA }^{\circ}\end{array}$ & 3.5 & 2.72 & 14 to 18 & Sunlight & $\begin{array}{l}\text { Dilute sewage in } \\
\text { freshwater; human } \\
\text { or bovine feces } \\
\text { into freshwater }\end{array}$ & $\begin{array}{l}\text { Ahmed et al. } 2014 \\
\text {; Liang et al., } 2012\end{array}$ \\
\hline $\begin{array}{l}\text { Human Specific } \\
\text { Bacteroides HF183 }\end{array}$ & 1.7 to 2.3 & 2.53 & 15 to 20 & Dark & NR & $\begin{array}{c}\text { Dick et al., 2010; } \\
\text { Jeanneau et al., } \\
2012\end{array}$ \\
\hline $\begin{array}{l}\text { Human Specific } \\
\text { Bacteroides HF183 }\end{array}$ & NR & 1.71 to 2.78 & 25 & Dark & NR & Dick et al., 2010 \\
\hline $\begin{array}{l}\text { Human Specific } \\
\text { Bacteroides HF183 } \\
\text { RNA }^{\mathrm{C}}\end{array}$ & NR & 2.08 & 15 & Sunlight & NR & Liang et al., 2012 \\
\hline $\begin{array}{l}\text { Human Specific } \\
\text { Bacteroidales } \\
\text { HF183- 16s RNA } \\
\text { gene }^{\mathrm{c}}\end{array}$ & $>3$ & NR & 14 to 15 & Sunlight & $\begin{array}{c}\text { River water } \& \\
\text { primary effluent } \\
\text { (1:1 ratio) }\end{array}$ & $\begin{array}{c}\text { Korajkic et al. } \\
2014\end{array}$ \\
\hline $\begin{array}{l}\text { Human Specific } \\
\text { Bacteroidales } \\
\text { HF183- 16s RNA }_{\text {gene }^{\mathrm{c}}}\end{array}$ & $>3$ & NR & 14 to 15 & Sunlight & $\begin{array}{l}\text { River water } \& \\
\text { primary effluent } \\
\text { (1:1 ratio) }\end{array}$ & $\begin{array}{c}\text { Korajkic et al. } \\
2014\end{array}$ \\
\hline $\begin{array}{l}\text { Human Specific } \\
\text { Bacteroidales } \\
\text { HF183- 16s RNA }_{\text {gene }^{\mathrm{c}}}\end{array}$ & $>3$ & NR & 14 to 15 & Dark & $\begin{array}{l}\text { River water \& } \\
\text { primary effluent } \\
\text { (1:1 ratio) }\end{array}$ & $\begin{array}{c}\text { Korajkic et al. } \\
2014\end{array}$ \\
\hline $\begin{array}{l}\text { Human Specific } \\
\text { Bacteroidales } \\
\text { HF183- 16s RNA } \\
\text { gene }^{\mathrm{c}}\end{array}$ & $>3$ & NR & 14 to 15 & Dark & $\begin{array}{l}\text { River water } \& \\
\text { primary effluent } \\
\text { (1:1 ratio) }\end{array}$ & $\begin{array}{c}\text { Korajkic et al. } \\
2014\end{array}$ \\
\hline $\begin{array}{l}\text { Human Specific } \\
\text { Bacteroides } \\
\text {-BacHum }^{\mathrm{C}}\end{array}$ & NR & 2.35 & 15 & Dark & NR & Dick et al., 2010 \\
\hline $\begin{array}{l}\text { Human Specific } \\
\text { Bacteroides } \\
\text {-BacHum }^{\circ}\end{array}$ & NR & 1.74 to 3.03 & 25 & Dark & NR & Dick et al., 2010 \\
\hline $\begin{array}{l}\text { Human Specific } \\
\text { Bacteroides } \\
\text {-BacHum }\end{array}$ & NR & 1.54 & 25 & Light source & NR & Dick et al., 2010 \\
\hline $\begin{array}{l}\text { HumM2- } \\
\text { Bacteroidales-like } \\
\text { putative s factor }\end{array}$ & $>3$ & NR & 14 to 15 & Sunlight & $\begin{array}{l}\text { River water \& } \\
\text { primary effluent } \\
\text { (1:1 ratio) }\end{array}$ & $\begin{array}{l}\text { Korajkic et al. } \\
2014\end{array}$ \\
\hline
\end{tabular}




\begin{tabular}{|c|c|c|c|c|c|c|}
\hline Bacteria Type $^{a}$ & $\begin{array}{l}\text { T90 } \\
\text { (Days) }\end{array}$ & $\begin{array}{c}\text { T99 } \\
\text { (Days) }\end{array}$ & $\begin{array}{c}\text { Temperature } \\
\left({ }^{\circ} \mathrm{C}\right)\end{array}$ & Light Source & Comments & References \\
\hline $\begin{array}{l}\text { HumM2- } \\
\text { Bacteroidales-like } \\
\text { putative s factor }^{c}\end{array}$ & $>3$ & NR & 14 to 15 & Sunlight ${ }^{\mathrm{e}}$ & $\begin{array}{c}\text { River water \& } \\
\text { primary effluent } \\
\text { (1:1 ratio) }\end{array}$ & $\begin{array}{c}\text { Korajkic et al. } \\
2014\end{array}$ \\
\hline $\begin{array}{l}\text { HumM2- } \\
\text { Bacteroidales-like } \\
\text { putative s factor }^{c}\end{array}$ & $>3$ & NR & 14 to 15 & Dark & $\begin{array}{l}\text { River water \& } \\
\text { primary effluent } \\
\text { (1:1 ratio) }\end{array}$ & $\begin{array}{c}\text { Korajkic et al. } \\
2014\end{array}$ \\
\hline $\begin{array}{l}\text { HumM2- } \\
\text { Bacteroidales-like } \\
\text { putative s factor }^{c}\end{array}$ & $>3$ & NR & 14 to 15 & Dark $^{\mathrm{e}}$ & $\begin{array}{c}\text { River water \& } \\
\text { primary effluent } \\
\text { (1:1 ratio) }\end{array}$ & $\begin{array}{c}\text { Korajkic et al. } \\
2014\end{array}$ \\
\hline Salmonella & 47.9 to 95.8 & NR & 15 & Dark & NR & Boehm et al., 2012 \\
\hline Salmonella & 0.015 to 0.025 & NR & 15 & Light & NR & Boehm et al., 2012 \\
\hline
\end{tabular}

${ }^{a}$ Unless specified otherwise, all data presented are from cultured organisms and were not monitored using molecular methods; ${ }^{b}$ NR: Not Reported; ${ }^{c}$ Detected/ monitored using molecular methods; ${ }^{\mathrm{d}}$ Although these organisms are frequently detected via molecular methods, in this case the organism was cultured; ${ }^{\mathrm{e}}$ In presence of indigenous river microbiota

In studies by Liang et al. (2012) and Lothigius et al. (2010), bovine, human, and pathogenic strains of E. coli spp. all persisted longer than generic E.coli spp in the experiments conducted. This is an important observation, as E. coli spp. is frequently used as an indicator of human excreta and may not be an appropriate surrogate for looking at the survival of specific strains of E.coli, particularly those that may be human pathogens. Lothigius et al. (2010) report that Enterotoxigenic E. coli (ETEC) had a T99 of 69.5 days at $21^{\circ} \mathrm{C}$ under natural sunlight conditions. In a similar study at $25^{\circ} \mathrm{C}$, E. coli spp. had a T99 of only 2.18 days (Dick et al. 2010).

Rodríguez and Araujo (2012) found that Campylobacter persists longer at lower temperatures $\left(4\right.$ to $\left.10^{\circ} \mathrm{C}\right)$, than at higher temperatures $\left(>20^{\circ} \mathrm{C}\right)$. This was also consistent with the findings of Schang et al., (2016). The persistence further increased when the organism was studied under dark conditions and decreased when subjected to sunlight. The T90s of Campylobacter ranged from 4.08 days under cold $\left(4^{\circ} \mathrm{C}\right)$ dark conditions to as little as 0.43 days when exposed to sunlight and when temperatures reached $22.3^{\circ} \mathrm{C}$ (Table 5). A T90 of 0.46 days was also achieved in dark conditions when temperatures rose to $37^{\circ} \mathrm{C}$ (Rodríguez and Araujo, 2012).

In work by Boehm et al. (2012), Salmonella spp. was shown to be extremely sensitive to sunlight. Under dark conditions at $15^{\circ} \mathrm{C}$, Salmonella spp. was shown to survive from between 47.9 to 95.8 days before seeing a $1 \log _{10}$ dieoff. Under the same temperature conditions but under sunlight, the organism showed a $1 \log _{10}$ die-off within a matter of hours (Table 5).

Several studies have been conducted on the survival and persistence of Bacteroides species by either culture or molecular techniques. Balleste and Blanch (2010) reported that $B$. fragilis die-off (by culture) was affected by high temperatures and the presence of other environmental predators. They studied the effect of environmental predators by comparing the persistence of $B$. fragilis in sterile river water and non-sterile river water. $B$. fragilis survived for longer in the sterilized water compared to the natural river water (Balleste and Blanch 2010). They also observed the lowest T90 values for $B$. fragilis when temperature and DO concentrations were the highest (Balleste and Blanch, 2010). In contrast, they found that $B$. thetaiotaomicron and environmental Bacteroides spp. were more affected by the concentration of DO in the water and could survive longer when DO concentrations were lower and temperatures were higher. In addition, they reported that environmental Bacteroides spp. (by culture) died off more rapidly than indicator organisms such as fecal coliforms and fecal enterococci, thus suggesting that the presence of Bacteroides spp. in surface water supplies could be a good indicator of recent fecal contamination. Finally, when using molecular techniques, it was found in the same experiments that temperature significantly affected the detection of Bacteroides DNA in the water samples. In summer months, they were only detected occasionally, therefore potentially producing false negative results. These findings seem to be consistent with those of Dick et al. (2010) and Liang et al. (2012) who reported similar die-off times to achieve 2 log removal (using molecular detection methods) as the die-off times reported by Balleste and Blanch (2010) to achieve only a $1 \log _{10}$ reduction (using culture-based detection methods). The DNA seems to degrade more rapidly than culturable organisms.

In a recent study by Korajikic et al. (2014) that looked at four genetic human-associated MST markers (Enterola, GenBac3, HF183, HumM2), they found that the organisms' RNA persisted for between 3 to 5 days in river water. Interestingly, they found little difference between the persistence of the genetic material under different environmental conditions (sunlight, dark, in the presence and absence of indigenous river microbiota) (Korajikic et al., 2014). In contrast, in the same study they observed a more rapid die-off of culturable enterococci (T90 < 3 days) for all environmental conditions except the die-off was less rapid in the dark (T90 $>3$ days to $<5$ days). E.coli persisted longer than enteroccocci and under all environmental conditions studied took greater than 5 days for a $1 \log _{10}$ dieoff to be observed (Korajikic et al., 2014). These data presented herein raise an important question of whether 
organism survival should be evaluated using molecular techniques.

\subsection{Protozoa and protozoan indicators}

Only two studies were found that examined the persistence of protozoa in surface water (Ives et al., 2007; Sidhu et al., 2015) (Table 6). These studies examined the survival of Cryptosporidium under dark conditions at various temperatures. The organism seems to be extremely sensitive to temperature. It was shown to survive for greater than 200 days at $5^{\circ} \mathrm{C}$, whereas a $2 \log _{10}$ reduction was achieved in 10 to 11 days at $30^{\circ} \mathrm{C}$ (Ives et al., 2007). Although no studies were found on the persistence of the organism in sunlight conditions, it has been established that Cryptosporidium can be inactivated by UV disinfection (Morita et al., 2002), therefore it is expected that under sunlight conditions, die-off would be more rapid in the environment. More data is needed on the survival of Cryptosporidium and Giardia in surface waters under a variety of environmental conditions.

Table 6. Summary of the persistence of the protozoan Cryptosporidium parvum in fresh surface waters under different temperatures conditions in the dark

\begin{tabular}{lcccc}
\hline \multicolumn{1}{c}{$\begin{array}{c}\text { T90 } \\
\text { (Days) }\end{array}$} & $\begin{array}{c}\text { T99 } \\
\text { (Days) }\end{array}$ & Temperature $\left({ }^{\circ} \mathbf{C}\right)$ & References \\
\hline $\mathrm{NR}^{\mathrm{a}}$ & $>200$ & 5 & Ives et al., 2007 \\
$38^{\mathrm{b}, \mathrm{c}}$ to $86^{\mathrm{d}}$ & 30 to $45^{\mathrm{d}}$ & 20 to 25 & Ives et al., 2007; Sidhu et al. 2015 \\
$\mathrm{NR}$ & 10 to 11 & 30 & Ives et al., 2007
\end{tabular}

${ }^{\mathrm{a} N R}$ : Not Reported; ${ }^{\mathrm{b}}$ Sidhu and Toze, 2012; ' Sidhu et al. 2015; ${ }^{\mathrm{d}}$ Ives et al., 2007

\subsection{Viruses and viral indicators}

Long and Sobsey (2004) conducted an extensive study on the survival of several types of bacteriophages in surface water under dark conditions at both $4^{\circ} \mathrm{C}$ and $20^{\circ} \mathrm{C}$ (Table 7). All the bacteriophage strains studied were sensitive to temperature; all of them survived longer at $4^{\circ} \mathrm{C}$ than at $20^{\circ} \mathrm{C}$. The T99s at $4^{\circ} \mathrm{C}$ ranged from 7.3 days to 250 days, whereas, the T99s at $20^{\circ} \mathrm{C}$ only ranged from 1.7 to 35 days. These observations were consistent for poliovirus and human adenoviruses, whose survival decreased with increasing temperatures and also decreased further when exposed to sunlight or UVA/ UVB radiation (Table 8). It is difficult to compare the bacteriophage data with the virus data as all the bacteriophage experiments were conducted in the dark, whereas most of the virus experiments were performed under sunlight or under UV radiation. In one case, an experiment was done with human adenoviruses under dark conditions and Rigotto et al. (2011) showed that it could survive over 301 days at $19^{\circ} \mathrm{C}$ (Table 8). This survival surpasses the most persistent bacteriophage survival by nearly 10 -fold under the same temperature and light conditions, thus suggesting that bacteriophage would not be a good surrogate organism for adenoviruses. Adenoviruses do seem to be affected by temperature, and are less persistent at lower temperatures $\left(10^{\circ} \mathrm{C}\right)$ and higher temperatures $\left(37^{\circ} \mathrm{C}\right)$ than moderate temperatures $\left(19^{\circ} \mathrm{C}\right)$ (Table 8$)$. 
Table 7. Summary of the persistence of bacteriophage in fresh surface waters under different temperatures conditions in the dark

\begin{tabular}{|c|c|c|c|}
\hline Type of Phage & RNA or DNA & T99 (Days) & $\begin{array}{c}\text { Temperature } \\
\left({ }^{\circ} \mathrm{C}\right)\end{array}$ \\
\hline f1 & DNA & 70 & 4 \\
\hline $\mathrm{fd}$ & DNA & 57 & 4 \\
\hline M13 & DNA & 220 & 4 \\
\hline OW & DNA & 33 & 4 \\
\hline SD & DNA & 20 & 4 \\
\hline $\mathrm{ZJ} / 2$ & DNA & 76 & 4 \\
\hline Dm3 & RNA & 8.3 & 4 \\
\hline Go1 & RNA & 250 & 4 \\
\hline Ms2 & RNA & 240 & 4 \\
\hline SG1 & RNA & 171 & 4 \\
\hline SG4 & RNA & 8.3 & 4 \\
\hline SG42 & RNA & 7.3 & 4 \\
\hline Sp2 & RNA & 51.5 & 4 \\
\hline f1 & DNA & 10 & 20 \\
\hline $\mathrm{fd}$ & DNA & 7.4 & 20 \\
\hline M13 & DNA & 35 & 20 \\
\hline OW & DNA & 5.4 & 20 \\
\hline SD & DNA & 3.2 & 20 \\
\hline $\mathrm{ZJ} / 2$ & DNA & 8.8 & 20 \\
\hline Go1 & RNA & 25 & 20 \\
\hline Ms2 & RNA & 29 & 20 \\
\hline SG1 & RNA & 23 & 20 \\
\hline SG4 & RNA & 1.7 & 20 \\
\hline SG42 & RNA & 1.6 & 20 \\
\hline Sp2 & RNA & 12 & 20 \\
\hline
\end{tabular}

Source: Long and Sobsey, 2004 
Table 8. Summary of the persistence of viruses in fresh surface waters under different temperature and light conditions

\begin{tabular}{|c|c|c|c|c|c|c|c|}
\hline Virus Type $^{\mathbf{a}}$ & $\begin{array}{c}\text { T90 } \\
\text { (Days) }\end{array}$ & $\begin{array}{c}\text { T99 } \\
\text { (Days) }\end{array}$ & $\begin{array}{l}\text { T99.9 } \\
\text { (Days) }\end{array}$ & $\begin{array}{l}\text { T99.99 } \\
\text { (Days) }\end{array}$ & Temperature $\left({ }^{\circ} \mathrm{C}\right)$ & $\begin{array}{l}\text { Light } \\
\text { Source } \\
\end{array}$ & References \\
\hline Feline calicivirus & 4.2 to $7.1^{\mathrm{C}}$ & 8.3 to $14.3^{\mathrm{C}}$ & 12.5 to $21.4^{\mathrm{C}}$ & 16.7 to $28.6^{\mathrm{C}}$ & 4 & Dark & $\begin{array}{l}\text { Bae and Schwab, } \\
2008\end{array}$ \\
\hline Feline calicivirus & 1.9 to $3.8^{\mathrm{C}}$ & 3.7 to $7.7^{\mathrm{C}}$ & 5.6 to $11.5^{\mathrm{C}}$ & 7.4 to $15.4^{\mathrm{C}}$ & 25 & Dark & $\begin{array}{l}\text { Bae and Schwab, } \\
2008\end{array}$ \\
\hline $\begin{array}{l}\text { Human } \\
\text { Adenovirus- } \\
\text { type } 2\end{array}$ & 0.03 & 0.07 & 0.17 & 0.20 & 7 & JVB Radiation & $\begin{array}{l}\text { Carratalà et al., } \\
2013\end{array}$ \\
\hline $\begin{array}{l}\text { Human } \\
\text { Adenovirus }\end{array}$ & 30 to 40 & NR & NR & NR & 10 & Dark & Rigotto et al., 2011 \\
\hline $\begin{array}{l}\text { Human } \\
\text { Adenovirus- } \\
\text { qPCR }^{b}\end{array}$ & NR & 13 & NR & NR & 14 to 18 & Sunlight & Ahmed et al.,2014 \\
\hline Human Adenovirus & 161 & NR & NR & 301 & 19 & Dark & Rigotto et al., 2011 \\
\hline $\begin{array}{l}\text { Human } \\
\text { Adenovirus- } \\
\text { type } 2\end{array}$ & 0.57 & 1.26 & 1.96 & 2.66 & 20 & JVA Radiation & $\begin{array}{c}\text { Carratalà et al., } \\
2013\end{array}$ \\
\hline $\begin{array}{l}\text { Human } \\
\text { Adenovirus- } \\
\text { type } 2\end{array}$ & 0.45 & 0.79 & 1.10 & 1.42 & 37 & Dark & $\begin{array}{l}\text { Carratalà et al., } \\
\qquad 2013\end{array}$ \\
\hline $\begin{array}{l}\text { Human } \\
\text { Adenovirus- } \\
\text { type } 2\end{array}$ & 0.29 & 0.57 & 0.85 & 1.14 & 37 & JVA Radiation & $\begin{array}{l}\text { Carratalà et al., } \\
2013\end{array}$ \\
\hline Human Adenovirus & NR & NR & NR & 5 & 37 & Dark & Rigotto et al., 2011 \\
\hline Murine norovirus & 4.5 to $10^{\mathrm{C}}$ & 9.1 to $20^{\mathrm{C}}$ & 13.6 to $30^{\mathrm{C}}$ & 18.2 to $40^{\mathrm{C}}$ & 25 & Dark & $\begin{array}{l}\text { Bae and Schwab, } \\
2008\end{array}$ \\
\hline Tulane virus & NR & NR & NR & 28 & 4 & Dark & $\begin{array}{l}\text { Arthur and Gibson, } \\
2015\end{array}$ \\
\hline
\end{tabular}

${ }^{a}$ Unless specified otherwise, all data presented are from cultured organisms and were not monitored using molecular methods; ${ }^{b}$ Detected/ monitored using molecular methods; ${ }^{\mathrm{c}}$ Calculated from $\log _{10} /$ day reduction values reported in the paper; ${ }^{d}$ NR: Not Reported 


\subsection{Persistence in Groundwater}

Tables 9,10,11, and 12 summarized the findings of the persistence of microorganisms in groundwater under varying temperatures. Survival/ die-off data are reported as T90 or T99 values. For groundwater, all experiments were performed in the dark.

Of the 45 articles retained in the review, 15 focused on the survival of indicator organisms or pathogens in groundwater supplies. Most of the data found in these articles was on the persistence of viruses and bacteriophages in groundwater (16 types of viruses/ bacteriophages). Only 3 articles presented data on protozoa and 4 articles presented data on bacterial pathogens or indicator organisms.

\subsection{Bacteria and bacterial indicators}

Data on the persistence of Campylobacter jejuni, Salmonella spp., Salmonella typhimurium, and indicator bacteria such as coliforms, E.coli spp., or Enterococci are reported in Table 9. Of the organisms studied, E.coli spp. was the most persistent at low temperatures $\left(0\right.$ to $\left.4^{\circ} \mathrm{C}\right)$. In experiments at low temperatures $\left(0\right.$ to $\left.4{ }^{\circ} \mathrm{C}\right)$, E.coli was found to have a T99 of 91 to 119 days. In the same experiment Campylobacter jejuni had a T99 of only 15 to 21 days. In contrast, in another study at 20 to $25^{\circ} \mathrm{C}$, E.coli spp. was found to have a T90 of 0.025 to 24.39 days, while, Salmonella typhimurium took between 1 to 18.51 days to have the same die-off. These data highlighted that using E.coli spp. as a representative indicator organism for understanding of persistence of bacterial pathogens in groundwater supplies will need to be specific to the bacterial pathogen under study. These results suggest that E.coli may be representative of Salmonella in groundwater, however not of $C$. jejuni. John and Rose (2005) highlighted that increased temperature can contribute to the inactivation of bacteria in groundwater, however, this issue is more complex as some coliform bacteria have shown to thrive and replicate in waters of higher temperatures if sufficient nutrients are available. For example, the presence of competing organisms, nutrient availability, and the presence of other compounds in the water may all be temperature dependent and therefore temperature on its own is not the only factor to consider when examining bacterial persistence. More research is needed on the survival of bacterial pathogens under different environmental conditions in groundwater.

In addition to temperature, Cook and Bolster (2007) examined the influence of dissolved organic carbon (DOC) and dissolved total nitrogen on the persistence of $C$. jejuni and E.coli. They found that $C$. jejuni survived the longest when the DOC was the highest $(4.0 \mathrm{mg} / \mathrm{L})$. Interestingly, E.coli survived longer in experiments where the DOC was the lowest, but the total dissolved nitrogen was the highest.

Dissolved oxygen (DO) is another environmental factor that can affect the inactivation of organisms in groundwater supplies (John and Rose, 2005). Data on DO are lacking, however research by Gordon and Toze (2003) suggest that E.coli inactivation was slightly reduced under anaerobic conditions compared to aerobic conditions.

Table 9. Summary of the persistence of bacteria and indicator bacteria in groundwater under different temperatures conditions in the dark

\begin{tabular}{|c|c|c|c|c|}
\hline Bacteria Type $^{\text {a }}$ & $\begin{array}{c}\text { T90 } \\
\text { (Days) }\end{array}$ & $\begin{array}{c}\text { T99 } \\
\text { (Days) }\end{array}$ & $\begin{array}{c}\text { Temperature } \\
\left({ }^{\circ} \mathrm{C}\right) \\
\end{array}$ & References \\
\hline Campylobacter jejuni & NR & 15 to 21 & 0 to 4 & Cook and Bolster, 2007 \\
\hline Coliform & $20^{\mathrm{b}}$ & $40^{\mathrm{b}}$ & 0 to 10 & John and Rose, 2005 \\
\hline Coliform & $10^{b}$ & $20^{b}$ & 15 to 20 & John and Rose, 2005 \\
\hline Coliform & $10^{b}$ & $20^{b}$ & 21 to 37 & John and Rose, 2005 \\
\hline E. coli spp. & NR & 91 to 119 & 0 to 4 & Cook and Bolster, 2007 \\
\hline E. coli spp. & 1.1 to 1.4 & NR & 10 to 19 & Gordon and Toze, 2003 \\
\hline E. coli spp. & 1 to 24.39 & NR & 20 to 25 & $\begin{array}{c}\text { Sidhu et al., 2015; Sidhu } \\
\text { and Toze, } 2012\end{array}$ \\
\hline Enterococci & $10^{b}$ & $20^{\mathrm{b}}$ & 3 to 22 & John and Rose, 2005 \\
\hline Enterococcus Fecalis & 1 to 9.17 & NR & 20 to 25 & $\begin{array}{l}\text { Sidhu et al., 2015; Sidhu } \\
\text { and Toze, } 2012\end{array}$ \\
\hline Salmonellla spp & 1.43 to $10^{\mathrm{b}}$ & 2.85 to $20^{b}$ & 10 to 22 & John and Rose, 2005 \\
\hline $\begin{array}{l}\text { Salmonella } \\
\text { Typhimurium }\end{array}$ & 1 to 18.51 & NR & 20 to 25 & $\begin{array}{l}\text { Sidhu et al., 2015; Sidhu } \\
\text { and Toze, } 2012\end{array}$ \\
\hline
\end{tabular}

${ }^{a}$ Unless specified otherwise, all data presented are from cultured organisms and were not monitored using molecular methods; ${ }^{\mathrm{b}}$ Calculated from $\log _{10} /$ day reduction values reported in the paper; ${ }^{\mathrm{C}} \mathrm{NR}$ : Not Reported 


\subsection{Protozoa and protozoan indicators}

Three studies have examined the persistence of Cryptosporidium in groundwater. At low temperatures it can take $>200$ days for a $2 \log _{10}$ removal (Table 10 ). Between 20 to $25^{\circ} \mathrm{C}$, a die-off of $2 \log _{10}$ was reported between 48 and $>200$ days. Cryptosporidium seems to be less persistent in warmer temperatures $\left(26\right.$ to $\left.36^{\circ} \mathrm{C}\right)$ as Ives et al. (2007) reported a $2 \log _{10}$ die off in 17 to 18 days. These elevated temperatures are less likely to be observed in environmental groundwater except in the case of hot springs. Consequently, in groundwater supplies used for drinking water, Cryptosporidium may persist for extremely long periods of time. The author was unable to find any data on the survival of Giardia in groundwater. This is a significant research gap that needs to be filled.

Table 10. Summary of the persistence of the protozoan Cryptosporidium parvum in groundwater under different temperatures conditions in the dark

\begin{tabular}{lccc}
\hline $\begin{array}{c}\text { T90 } \\
\text { (Days) }\end{array}$ & $\begin{array}{c}\text { T99 } \\
\text { (Days) }\end{array}$ & $\begin{array}{c}\text { Temperature } \\
\left({ }^{\mathbf{(}} \mathbf{C}\right)\end{array}$ & References \\
\hline $\mathrm{NR}^{\mathrm{a}}$ & $>200$ & 5 to 9 & Ives et al., 2007 \\
$31^{\mathrm{b}}$ to $120^{\mathrm{c}}$ & $48^{\mathrm{d}}$ to $>200^{\mathrm{d}}$ & 20 to 25 & $\begin{array}{c}\text { Ives et al., 2007; Sidhu et al., 2015; } \\
\text { Sidhu and Toze, 2012 } \\
\mathrm{NR}\end{array}$ \\
17 to 18 & 30 & Ives et al., 2007
\end{tabular}

${ }^{\mathrm{a}}$ NR: Not Reported; ${ }^{\mathrm{b}}$ Sidhu and Toze, 2012; ${ }^{\mathrm{c}}$ Sidhu et al., 2015; ${ }^{\mathrm{d}}$ Ives et al. 2007

\subsection{Viruses and viral indicators}

In general, this review found that bacteriophages (Table 11) are less persistent in groundwater than viruses (Table 12 ), suggesting that bacteriophage may not be an appropriate surrogate organism for studying the survival of viruses in groundwater. For instance, in a study of GA bacteriophage (an RNA bacteriophage) in groundwater, it was found that at $4^{\circ} \mathrm{C}$ it took 19.9 days to have a $1 \log _{10}$ reduction (Ogorzaly et al., 2010). At the same temperature, other viruses such as adenovirus or rotavirus were shown to persist for 131.6 days and between 34 to 200 days, respectively, before experiencing a $1 \log _{10}$ reduction. Lopman et al. (2012) reported that noroviruses can survive up to 2 months in groundwater supplies and Seitz et al. (2011) found them to be still infectious after 60 days. Consequently, in these cases, using GA bacteriophage data to simulate persistence of pathogenic RNA viruses could significant underestimate the survival and subsequent public health risk associated with the persistence of viruses in groundwater supplies.

Table 11. Summary of the persistence of bacteriophage in groundwater under different temperatures conditions in the dark

\begin{tabular}{|c|c|c|c|}
\hline Bacteriophage Type $^{\mathrm{a}}$ & $\begin{array}{c}\text { T90 } \\
\text { (Days) }\end{array}$ & Temperature $\left({ }^{\circ} \mathrm{C}\right)$ & References \\
\hline Coliphage & 10 to $33.3^{b}$ & 4 to 30 & John and Rose, 2005 \\
\hline GA & 19.9 & 0 to 4 & Ogorzaly et al., 2010 \\
\hline GA & 1.2 & 20 to 25 & Ogorzaly et al., 2010 \\
\hline MS2 & $23.4^{\mathrm{c}}$ to $37^{\mathrm{d}}$ & 0 to 4 & $\begin{array}{c}\text { Bae and Schwab, } 2008^{\mathrm{e}} \text {; Yates et al. } \\
\text { 1985; Ogorzaly et al., } 2010\end{array}$ \\
\hline MS2 & $1^{\mathrm{f}}$ to $33^{\mathrm{d}}$ & 10 to 19 & $\begin{array}{c}\text { Gordon and Toze, 2003; Yates et al. } \\
1985\end{array}$ \\
\hline MS2 & $1.4^{\mathrm{c}}$ to $3^{\mathrm{d}}$ & 20 to 25 & $\begin{array}{c}\text { Bae and Schwab, } 2008^{\mathrm{e}} \text {; Yates et al. } \\
1985\end{array}$ \\
\hline MS2 & $2.7^{\mathrm{f}}$ to $8.2^{\mathrm{f}}$ & 26 to 36 & $\begin{array}{c}\text { Bae and Schwab, } 2008^{\mathrm{e}} \text {; Gordon and } \\
\text { Toze, } 2003\end{array}$ \\
\hline
\end{tabular}

${ }^{a}$ Unless specified otherwise, all data presented are from cultured organisms and were not monitored using molecular methods; ${ }^{b}$ Calculated from $\log _{10} /$ day reduction values reported in the paper; ${ }^{\text {c }}$ Ogorzaly et al., $2010 ;{ }^{\mathrm{d}}$ Yates et al. $1985 ;{ }^{\text {e }}$ Bae and Schwab, 2008 report results as $\log _{10} /$ day reductions ; calculated values for T90s fall within the ranges reported in the table; ${ }^{\text {f }}$ Gordon and Toze, 2003 
Table 12. Summary of the persistence of viruses in groundwater under different temperatures conditions in the dark

\begin{tabular}{|c|c|c|c|}
\hline Virus type & $\begin{array}{c}\text { T90 } \\
\text { (days) }\end{array}$ & Temperature $\left({ }^{\circ} \mathrm{C}\right)$ & References \\
\hline Adenovirus $^{\mathrm{n}}$ & $\begin{array}{c}131.6^{\mathrm{b}} \text { to } \\
>160^{\mathrm{c}}\end{array}$ & 4 & $\begin{array}{c}\text { Enriquez et al., 1994; Ogorzaly et al., } \\
\text { 2010; Rigotto et al., } 2011\end{array}$ \\
\hline Adenovirus & $160^{\mathrm{c}}$ & $10^{\mathrm{c}}$ to $19^{\mathrm{c}}$ & Rigotto et al., 2011 \\
\hline Adenovirus $^{\circ}$ & NR & 15 & Enriquez et al., 1994 \\
\hline Adenovirus & $35.6^{\mathrm{b}}$ to $>200^{\mathrm{e}}$ & $20^{\mathrm{b}, \mathrm{e}}$ to $25^{\mathrm{e}}$ & Ogorzaly et al., 2010; Sidhu et al., 2015 \\
\hline Adenovirus $^{\mathrm{p}}$ & NR & $23^{\mathrm{d}}$ & Enriquez et al., 1994 \\
\hline Coxsackievirus & $16.7^{\mathrm{g}}$ & 0 to 20 & John and Rose, 2005 \\
\hline Coxsackievirus & $7.6^{\mathrm{e}, \mathrm{g}}$ to $10.5^{\mathrm{h}}$ & $12^{\mathrm{e}}$ to $15^{\mathrm{h}}$ & $\begin{array}{c}\text { Charles et al., 2009; Gordon and Toze, } \\
2003\end{array}$ \\
\hline Coxsackievirus & $17.3^{\mathrm{g}, \mathrm{i}}$ to $169^{\mathrm{f}}$ & $20^{g}$ to $25^{\mathrm{e}}$ & John and Rose, 2005; Sidhu et al., 2015 \\
\hline Coxsackievirus & 10.2 & 28 & Gordon and Toze, 2003 \\
\hline Coxsackievirus & $10^{\mathrm{g}}$ & 25 to 30 & John and Rose, 2005 \\
\hline Echovirus & $10^{\mathrm{g}}$ & 10 to 20 & John and Rose, 2005 \\
\hline Echovirus & $5.4^{\mathrm{g}}$ to $19.6^{\mathrm{g}}$ & 12 to 13 & Yates et al. 1985 \\
\hline Echovirus & $10^{\mathrm{g}}$ & 20 to 25 & John and Rose, 2005 \\
\hline Echovirus & $1.6^{\mathrm{g}}$ to $5.3^{\mathrm{g}}$ & $23^{\mathrm{i}}$ & Yates et al. 1985 \\
\hline Feline calicivirus & $8.3^{g}$ to $12.5^{g}$ & 4 & Bae and Schwab, 2008 \\
\hline Feline calicivirus & $5.6^{\mathrm{g}}$ to $11.1^{\mathrm{g}}$ & 20 to 25 & Bae and Schwab, 2008 \\
\hline Hepatitis A & $100^{g}$ & 0 to 10 & John and Rose, 2005 \\
\hline Hepatitis A & $33.3^{g}$ & 20 to 30 & John and Rose, 2005 \\
\hline Norovirus $^{1}$ & $50^{\mathrm{g}}$ & 4 & Bae and Schwab, 2008 \\
\hline Norovirus ${ }^{\mathrm{k}, 1}$ & $5^{\mathrm{g}, \mathrm{j}}$ to $1266^{\mathrm{m}}$ & $20^{\mathrm{m}}$ to $25^{\mathrm{j}}$ & Bae and Schwab, 2008; Seitz et al., 2011 \\
\hline Poliovirus & $50^{g}$ & 0 to 10 & John and Rose, 2005 \\
\hline Poliovirus & $12.5^{g}$ to $50^{g}$ & 4 & Bae and Schwab, 2008 \\
\hline Poliovirus & $13.7^{\mathrm{g}}$ & 12 & Charles et al., 2009 \\
\hline Poliovirus & $11.1^{\mathrm{g}}$ to $10^{\mathrm{g}}$ & 11 to 20 & John and Rose, 2005 \\
\hline Poliovirus & $10.8^{g}$ to $28.6^{g}$ & 12 to 18 & Yates et al. 1985 \\
\hline Poliovirus & 5 & 15 & Gordon and Toze, 2003 \\
\hline Poliovirus & $5^{g, i}$ to $11.1^{g, j}$ & $21^{\mathrm{i}}$ to $25^{\mathrm{i}}$ & $\begin{array}{l}\text { John and Rose, 2005; Bae and Schwab, } \\
2008\end{array}$ \\
\hline Poliovirus & $1.5^{\mathrm{g}}$ to $2.8^{\mathrm{g}}$ & 23 & Yates et al. 1985 \\
\hline Poliovirus & $2.5^{\mathrm{g}}$ & 26 to 36 & John and Rose, 2005 \\
\hline Poliovirus & 1 & 28 & Gordon and Toze, 2003 \\
\hline PRD-1 & $50^{g}$ & 0 to 10 & John and Rose, 2005 \\
\hline PRD-1 & $10^{\mathrm{g}}$ & 21 to 25 & John and Rose, 2005 \\
\hline Rotavirus & $2.5^{\mathrm{g}}$ & 3 to 15 & John and Rose, 2005 \\
\hline Rotavirus & 34 to $>200$ & 22 to 23 & Sidhu et al., 2015 \\
\hline Tulane virus & $2.6^{\mathrm{g}}$ & 2 to 6 & Arthur and Gibson, 2015 \\
\hline
\end{tabular}

NR: Not Reported; ${ }^{a}$ Unless specified otherwise, all data presented are from cultured organisms and were not monitored using molecular methods; ${ }^{\mathrm{b}}$ Ogorzaly et al., 2010; ${ }^{\mathrm{c}}$ Rigotto et al., 2011; ${ }^{\mathrm{d}}$ Enriquez et al., 1994 [experiments done in tap water, from a well water source (absent of chlorine)]; ${ }^{\mathrm{e}}$ Charles et al., 2009; ${ }^{\mathrm{f}} \mathrm{Sidhu}$ et al., 2015; ${ }^{\mathrm{g}} \mathrm{Cal}$ culated from $\log _{10} / \mathrm{day}$ reduction values reported in the paper; ${ }^{\mathrm{h}}$ Gordon and Toze, 2003; ${ }^{\mathrm{i}} \mathrm{John}$ and Rose, 2005; ${ }^{\mathrm{j}}$ Bae and Schwab, $2008{ }^{\mathrm{k}}$ Infectious after 60 days; ${ }^{1}$ Molecular methods used; ${ }^{\mathrm{m}}$ Seitz et al., 2011 ; $^{\mathrm{n}} \mathrm{T} 99$ of $92^{\mathrm{d}}$ to $304^{\mathrm{d}} ;{ }^{\mathrm{o}}$ T99 of $87^{\mathrm{d}}$ to $124^{\mathrm{d}} ;{ }^{\mathrm{p}}$ T99 of $16^{\mathrm{d}}$ to $84^{\mathrm{d}}$ 
In a comprehensive review conducted by John and Rose (2005), it was found that virus inactivation occurs more rapidly at higher temperatures $\left(>20^{\circ} \mathrm{C}\right)$ which is consistent with what was found in the present review (Table 12). Gordon and Toze (2003) reported that inactivation of poliovirus and coxsackievirus was much slower in anaerobic groundwater compared to aerobic conditions, whereas MS2 bacteriophage was inactivated more quickly in anaerobic conditions. It is possible that DO levels may be linked to the presence of other native organisms in the environment and thus could affect the persistence of viruses (John and Rose, 2005). The influence of DO on virus survival still needs further investigation.

\subsection{Persistence in Marine Waters}

Tables 13,14,15, and 16 summarized the findings of the survival of bacteria, protozoa, bacteriophage and viruses in brackish or saltwater under varying temperatures and light conditions. Survival/ die-off data are reported as T90, T99, or T99.9 values. These studies were performed in the dark, under light, and/or under natural sunlight conditions. In addition, some studies looked at the effect of UVA and UVB radiation specifically on organism survival.

In the present review, 16 of the 45 articles focused on the survival of indicator organisms or pathogens in saltwater. The majority of the data found in these articles was on the persistence of bacteria in saltwater (10 types of bacteria) followed by viruses ( 4 virus types) and then bacteriophage (1 type). Similar to the groundwater and surface water sections in this chapter, only 1 article was found on the persistence of protozoa.

\subsection{Bacteria and bacterial indicators}

From the literature presented in Tables 9 and 13, it appears that bacteria are less persistent in saltwater than surface fresh waters. Lothigius et al. (2010) reported that the survival of ETEC was significant affected by salinity in their experiments. A T99 of 8.75 days was observed in saline water compared to a T99 of 69.5 days in surface water. Chandran et al. (2013) reported that the persistence of Salmonella and E.coli was largely unaffected in brackish/ saline water until concentrations reached 25 ppt (parts per thousand)(Table 13). Seawater is approximately $35 \mathrm{ppt}$, therefore, suggesting that these organisms would not survive for very long in seawater but could survive in brackish waters. These findings are in line with Boehm et al. (2012) who reported a T90 of 0.017 to 0.025 for Salmonella in saltwater under sunlight conditions. Ahmed et al. (2014) conducted experiments in both freshwater and saltwater microcosms, they found that the fecal indicators enterococci, E.coli, and the microbial source tracking marker (MST) human Bacteroides (HF183) had a slightly faster inactivation rate in saltwater than freshwater (although not statistically significant). The Bacteroides marker had a similar decay rate as the fecal indicator organisms suggesting that it might be a reasonable indicator of recent fecal contamination (Ahmed et al., 2014). In contrast, Walters et al. (2009) reported that the human specific Bacteroidales marker persisted much longer (>18 days) than the culturable enterococci (5 days).

Table 13. Summary of the persistence of bacteria and indicator bacteria in saltwater or brackish water under different temperature and light conditions

\begin{tabular}{|c|c|c|c|c|c|}
\hline Bacteria Type & $\begin{array}{c}\text { T90 } \\
\text { (Days) }\end{array}$ & $\begin{array}{c}\text { T99 } \\
\text { (Days) }\end{array}$ & Temperature $\left({ }^{\circ} \mathrm{C}\right)$ & Light Source & References \\
\hline $\begin{array}{l}\text { Bacteriodales human } \\
\text { marker }^{\mathrm{b}}\end{array}$ & 1.77 & NR & 17 & Light & Walters et al. 2009 \\
\hline $\begin{array}{l}\text { Bacteriodales human } \\
\text { marker }^{\mathrm{b}}\end{array}$ & 8.72 & NR & 17 & Dark & Walters et al. 2009 \\
\hline $\begin{array}{l}\text { Bacteriodes HF183 } \\
\text { DNA }^{\text {b }}\end{array}$ & 2.7 & NR & 14 to 18 & Sunlight & Ahmed et al., 2014 \\
\hline $\begin{array}{l}\text { Catellicoccus } \\
\text { marimammalium } \\
\text { marker }\end{array}$ & $0.56^{\mathrm{d}}$ & NR & 8 to 12 & Dark & $\begin{array}{c}\text { Brown and Boehm, } \\
2015\end{array}$ \\
\hline $\begin{array}{l}\text { Clostridium } \\
\text { perfringens }\end{array}$ & $>1.3^{\mathrm{d}}$ & NR & 22 to 24 & Dark & Zhang et al. 2015 \\
\hline E.coli spp. & 9 to 10.7 & 14 & -2 to 0 & Dark & Smith et al., 1994 \\
\hline E.coli spp. & 1.7 & NR & 16.8 & Sunlight & Ahmed et al., 2014 \\
\hline E.coli spp. & 0.68 to $16.7^{\mathrm{d}}$ & NR & 22 to 24 & Dark & Zhang et al. 2015 \\
\hline
\end{tabular}




\begin{tabular}{|c|c|c|c|c|c|}
\hline Bacteria Type & $\begin{array}{c}\text { T90 } \\
\text { (Days) }\end{array}$ & $\begin{array}{c}\text { T99 } \\
\text { (Days) }\end{array}$ & Temperature $\left({ }^{\circ} \mathrm{C}\right)$ & Light Source & References \\
\hline E.coli spp. & NR & 16 to 22 & 20 to 30 & Nat. light cycle & $\begin{array}{c}\text { Chandran et al., } \\
2013\end{array}$ \\
\hline E. faecalis & NR & 8 to 35 & -2 to 0 & Dark & Smith et al., 1994 \\
\hline $\begin{array}{l}\text { Enterotoxigenic E. } \\
\text { coli }\end{array}$ & NR & 8.75 & 21 & Nat. light cycle & Lothigius et al., 2010 \\
\hline Fecal enterococci & 0.06 to $0.07^{\mathrm{d}}$ & NR & 8 to 12 & Nat. light cycle & $\begin{array}{c}\text { Brown and Boehm, } \\
2015\end{array}$ \\
\hline Fecal enterococci & 0.27 to $0.40^{\mathrm{d}}$ & NR & 8 to 12 & Dark & $\begin{array}{c}\text { Brown and Boehm, } \\
2015\end{array}$ \\
\hline Fecal enterococci & 1.04 to $1 . \mathrm{d}$ & NR & 14 to 18 & Sunlight & $\begin{array}{l}\text { Ahmed et al., 2014; } \\
\text { Walters et al. } 2009\end{array}$ \\
\hline Fecal enterococci & 1.32 to $5.56^{\mathrm{d}}$ & NR & 22 to 24 & Dark & Zhang et al. 2015 \\
\hline Fecal enterococci & 0.28 to 1.46 & NR & 16 to 20 & UV Radiation & Kay et al., 2005 \\
\hline Fecal enterococci & 0.63 to 2.54 & NR & 16 to 20 & Dark & $\begin{array}{l}\text { Kay et al., 2005; } \\
\text { Walters et al. } 2009\end{array}$ \\
\hline $\begin{array}{l}\text { Fecal enterococci } \\
\text { (qPCR) }^{\mathrm{b}}\end{array}$ & 0.19 to $0.44^{\mathrm{d}}$ & NR & 8 to 12 & Nat. light cycle & $\begin{array}{c}\text { Brown and Boehm, } \\
2015\end{array}$ \\
\hline $\begin{array}{l}\text { Fecal enterococci } \\
\text { (qPCR) }^{\mathrm{b}}\end{array}$ & $>0.4^{\mathrm{d}, \mathrm{e}}$ & NR & 8 to 12 & Dark & $\begin{array}{l}\text { Brown and Boehm, } \\
2015\end{array}$ \\
\hline Fecal coliforms & 0.88 to 2 & NR & 22 to 26 & Fluorescent & Fujioka et al., 1981 \\
\hline Fecal coliforms & 0.02 to 0.06 & NR & 22 to 26 & Sunlight & Fujioka et al., 1981 \\
\hline Fecal streptococci & 1.5 to 3.5 & NR & 22 to 26 & Fluorescent & Fujioka et al., 1981 \\
\hline Fecal streptococci & 0.04 to 0.13 & NR & 22 to 26 & Sunlight & Fujioka et al., 1981 \\
\hline $\begin{array}{l}\text { Salmonella } \\
\text { typhimurium }\end{array}$ & 4 to 11 & 17 to 22 & -2 to 0 & Dark & Smith et al., 1994 \\
\hline Salmonella enterica & 0.02 to 0.03 & NR & 15 & Light & Boehm et al., 2012 \\
\hline Salmonella enterica & 47.9 & NR & 15 & Dark & Boehm et al., 2012 \\
\hline Salmonella paratyphi & NR & 15 to 16 & 20 to 30 & Nat. light cycle & $\begin{array}{c}\text { Chandran et al., } \\
2013\end{array}$ \\
\hline
\end{tabular}

${ }^{a}$ Unless specified otherwise, all data presented are from cultured organisms and were not monitored using molecular methods; ${ }^{\mathrm{b}}$ Detected/ monitored using molecular methods; ${ }^{\mathrm{C}}$ NR: Not Reported; ${ }^{\mathrm{d}}$ Calculated from $\log _{10} /$ day reduction values reported in the paper; ${ }^{\mathrm{e}} \mathrm{Study}$ also reported zero die-off $\left(\log _{10} /\right.$ day reduction $=0$ )

Importantly, both Walters et al. (2009) and Ahmed et al. (2014) noted that human enteroviruses and adenoviruses, respectively, survived much longer than the bacteria in the seawater microcosm experiments. These findings highlight that when evaluating public health risk, it is important to rely on multiple microbial indicators, not only bacteria or traditional fecal indicator organisms. Similar to surface water, bacteria in saltwater are affected by sunlight and persist longer under dark conditions (Tables 9 and 13).

\subsection{Protozoa and protozoan indicators}

Similar to groundwater and surface water, very few data were found regarding the survival of protozoa in saltwater. In a study by Sidhu et al., (2015), it was found that Cryptosporidium oocysts survived significantly longer in brackish groundwater supplies (T90: 56 to 120 days) (Table 14) than non-brackish groundwater (T90: 38 days) at 22 to $23^{\circ} \mathrm{C}$ (Table 10 ).

Table 14. Summary of the persistence of the protozoan Cryptosporidium parvum in saltwater or brackish water between $20-25^{\circ} \mathrm{C}$ in the dark

\begin{tabular}{lccccc}
\hline \multicolumn{1}{c}{ Protozoa Type } & $\begin{array}{c}\text { T90 } \\
\text { (Days) }\end{array}$ & 56 to 120 & Temperature $\left({ }^{\circ} \mathbf{C}\right)$ & Light Source & References \\
\hline Cryptosporidium & 20 to 25 & Dark & Sidhu et al. 2015
\end{tabular}




\subsection{Viruses and viral indicators}

Flannery et al. (2013) compared the persistence of FRNA bacteriophage GA via culture and quantitative reverse transcription PCR (RT-qPCR) in seawater experiments (Table 15). They found that RT-qPCR significantly overestimates the survival of infectious bacteriophage, and therefore conclude that using RT-qPCR to estimate organism survival is inappropriate (Flannery et al. 2013). In addition, they examined the persistence of norovirus GI \& GII in seawater and found very little difference in their survival at 9 to $11^{\circ} \mathrm{C}$ under either sunlight or dark conditions (Table 16). Once temperatures reached 16 to $18^{\circ} \mathrm{C}$, norovirus inactivation was more rapid in sunlight (T90: 0.85 to 0.9 ) than in the dark (T90: 1.71 to 2.49). In a study by Seitz et al. (2011), it was found that norovirus could persist for extremely long times in groundwater at 20 to $25^{\circ} \mathrm{C}$ (T90: 1266 days). These results suggest that norovirus may be affected by salinity and persist for shorter periods of time in saltwater than freshwater sources, however more data are needed.

Table 15. Summary of the persistence of bacteriophage in saltwater or brackish water under different temperatures and light conditions

\begin{tabular}{|c|c|c|c|c|}
\hline Bacteriophage Type & $\begin{array}{c}\text { T90 } \\
\text { (Days) }\end{array}$ & Temperature $\left({ }^{\circ} \mathrm{C}\right)$ & Light Source & References \\
\hline $\begin{array}{l}\text { FRNA phage GA } \\
\text { (culture) }\end{array}$ & 0.63 & 9 to 11 & Dark & Flannery et al., 2013 \\
\hline $\begin{array}{l}\text { FRNA phage GA } \\
\text { (culture) }\end{array}$ & 0.17 & 9 to 11 & Sunlight & Flannery et al., 2013 \\
\hline $\begin{array}{l}\text { FRNA phage GA } \\
\text { (culture) }\end{array}$ & 0.22 to 2.10 & 16 to 18 & Dark & Flannery et al., 2013 \\
\hline $\begin{array}{l}\text { FRNA phage GA } \\
\text { (culture) }\end{array}$ & 0.01 & 16 to 18 & Sunlight & Flannery et al., 2013 \\
\hline $\begin{array}{l}\text { FRNA phage GA } \\
(\text { qPCR })^{b}\end{array}$ & 3.96 & 9 to 11 & Dark & Flannery et al., 2013 \\
\hline $\begin{array}{l}\text { FRNA phage GA } \\
\text { (qPCR) }^{\mathrm{b}}\end{array}$ & 3.25 & 9 to 11 & Sunlight & Flannery et al., 2013 \\
\hline $\begin{array}{l}\text { FRNA phage GA } \\
(\text { qPCR) }\end{array}$ & 2.1 & 16 to 18 & Dark & Flannery et al., 2013 \\
\hline $\begin{array}{l}\text { FRNA phage GA } \\
(\text { (qPCR) }\end{array}$ & 0.69 & 16 to 18 & Sunlight & Flannery et al., 2013 \\
\hline
\end{tabular}

${ }^{a}$ Unless specified otherwise, all data presented are from cultured organisms and were not monitored using molecular methods; ${ }^{\mathrm{b}}$ Detected/ monitored using molecular techniques

Table 16. Summary of the persistence of pathogenic and indicator organisms in saltwater or brackish water under different temperatures conditions

\begin{tabular}{|c|c|c|c|c|c|}
\hline $\begin{array}{c}\text { Specific Organism/ } \\
\text { Pathogen }\end{array}$ & $\begin{array}{c}\text { T90 } \\
\text { (Days) }\end{array}$ & $\begin{array}{c}\text { T99 } \\
\text { (Days) }\end{array}$ & Temperature $\left({ }^{\circ} \mathrm{C}\right)$ & Light Source & References \\
\hline Enterovirus & $>14$ & NR & 17 & Dark & $\begin{array}{l}\text { Walters et al. } \\
\quad 2009\end{array}$ \\
\hline Enterovirus & $>8$ & NR & 17 & Sunlight & $\begin{array}{l}\text { Walters et al. } \\
\quad 2009\end{array}$ \\
\hline Enterovirus (genome ) ${ }^{\mathrm{b}}$ & 16.4 & NR & 17 & Dark & $\begin{array}{l}\text { Walters et al. } \\
\quad 2009\end{array}$ \\
\hline Enterovirus (genome) ${ }^{\mathrm{b}}$ & 15.7 & NR & 17 & Sunlight & $\begin{array}{l}\text { Walters et al. } \\
\quad 2009\end{array}$ \\
\hline $\begin{array}{l}\text { Human Adenovirus- } \\
\text { type } 2\end{array}$ & 0.04 & 0.08 & 7 & UVB Radiation & $\begin{array}{c}\text { Carratalà et al. } \\
2013\end{array}$ \\
\hline
\end{tabular}




\begin{tabular}{|c|c|c|c|c|c|}
\hline $\begin{array}{c}\text { Specific Organism/ } \\
\text { Pathogen }\end{array}$ & $\begin{array}{c}\text { T90 } \\
\text { (Days) }\end{array}$ & $\begin{array}{c}\text { T99 } \\
\text { (Days) }\end{array}$ & Temperature $\left({ }^{\circ} \mathrm{C}\right)$ & Light Source & References \\
\hline $\begin{array}{l}\text { Human Adenovirus- } \\
\text { qPCR }^{b}\end{array}$ & 9.40 & NR & 13 to 18 & Sunlight & Ahmed et al., 2014 \\
\hline $\begin{array}{l}\text { Human Adenovirus } 40 \\
\& 41\end{array}$ & & 77 to 85 & 15 & Dark & $\begin{array}{c}\text { Enriquez et al., } \\
1994\end{array}$ \\
\hline $\begin{array}{l}\text { Human Adenovirus- } \\
\text { type } 2\end{array}$ & 0.28 & 0.64 & 20 & UVA Radiation & $\begin{array}{l}\text { Carratalà et al., } \\
2013\end{array}$ \\
\hline $\begin{array}{l}\text { Human Adenovirus- } \\
\text { type } 2\end{array}$ & 0.34 & 0.67 & 37 & Dark & $\begin{array}{l}\text { Carratalà et al., } \\
2013\end{array}$ \\
\hline $\begin{array}{l}\text { Human Adenovirus- } \\
\text { type } 2\end{array}$ & 0.23 & 0.57 & 37 & UVA Radiation & $\begin{array}{l}\text { Carratalà et al., } \\
2013\end{array}$ \\
\hline Norovirus GI by qPCR ${ }^{\mathrm{c}}$ & 3.58 & NR & 9 to 11 & Dark & $\begin{array}{c}\text { Flannery et al., } \\
2013\end{array}$ \\
\hline Norovirus GI by qPCR ${ }^{\mathrm{c}}$ & 3.72 & NR & 9 to 11 & Sunlight & $\begin{array}{c}\text { Flannery et al., } \\
2013\end{array}$ \\
\hline Norovirus GI by qPCR ${ }^{\mathrm{c}}$ & 2.49 & NR & 16 to 18 & Dark & $\begin{array}{c}\text { Flannery et al., } \\
2013\end{array}$ \\
\hline Norovirus GI by qPCR ${ }^{\mathrm{c}}$ & 0.90 & NR & 16 to 18 & Sunlight & $\begin{array}{c}\text { Flannery et al., } \\
2013\end{array}$ \\
\hline $\begin{array}{l}\text { Norovirus GII by } \\
\text { qPCR }^{c}\end{array}$ & 4.23 & NR & 9 to 11 & Dark & $\begin{array}{c}\text { Flannery et al., } \\
2013\end{array}$ \\
\hline $\begin{array}{l}\text { Norovirus GII by } \\
\text { qPCR }^{c}\end{array}$ & 3.50 & NR & 9 to 11 & Sunlight & $\begin{array}{l}\text { Flannery et al., } \\
2013\end{array}$ \\
\hline $\begin{array}{l}\text { Norovirus GII by } \\
\text { qPCR }^{c}\end{array}$ & 1.71 & NR & 16 to 18 & Dark & $\begin{array}{c}\text { Flannery et al., } \\
2013\end{array}$ \\
\hline $\begin{array}{l}\text { Norovirus GII by } \\
\text { qPCR }^{c}\end{array}$ & 0.85 & NR & 16 to 18 & Sunlight & $\begin{array}{c}\text { Flannery et al., } \\
2013\end{array}$ \\
\hline Poliovirus & NR & 18 & 15 & Dark & $\begin{array}{c}\text { Enriquez et al., } \\
1994\end{array}$ \\
\hline $\begin{array}{l}\text { Poliovirus (naked } \\
\text { genome) }^{\mathrm{c}}\end{array}$ & 32.4 & NR & 17 & Dark & $\begin{array}{l}\text { Walters et al. } \\
2009\end{array}$ \\
\hline $\begin{array}{l}\text { Poliovirus (naked } \\
\text { genome) }{ }^{c}\end{array}$ & 22.3 & NR & 17 & Sunlight & $\begin{array}{l}\text { Walters et al. } \\
2009\end{array}$ \\
\hline
\end{tabular}

${ }^{a}$ Unless specified otherwise, all data presented are from cultured organisms and were not monitored using molecular methods; ${ }^{\mathrm{b}} \mathrm{NR}$ : Not Reported; 'Infectious after 60 days

In seawater microcosms exposed to sunlight, Walters et al. (2009) studied the survival of enteroviruses via culture and through molecular methods. Infectious enteroviruses persisted for 8 days and the genetic enterovirus marker persisted for 28 days. Data are lacking on the survival of enteroviruses in surface water, therefore we are unable to assess the effect salinity may have on their persistence in environmental waters. It is clear that enteroviruses can persist longer in dark conditions than under sunlight (Table 16).

In studies of human adenovirus, there was no difference in the survival of adenoviruses between surface water, wastewater and seawater exposed to UVB radiation at $7^{\circ} \mathrm{C}$ (Carratalà et al., 2013). In the same study at $20^{\circ} \mathrm{C}$ under UVA radiation, adenoviruses decayed twice as fast in seawater (T90: 6.66) compared to surface water (T90: 13.96). Ahmed et al. (2014) also found that adenoviruses persisted longer in freshwater than saltwater at temperatures between 13 to $18^{\circ} \mathrm{C}$ under sunlight conditions.

\subsection{Data Gaps}

Temperature, sunlight, DO, DOC, availability of nutrients, and salinity were found to be important environmental conditions to consider when evaluating the persistence of microorganisms in environmental waters. This review was performed using a systematic methodology, however, it may not have included all the literature that exists on organism persistence in water matrices. Based on the literature recovered, very few data are available on the persistence of pathogens in aquatic environments.

Table 17 highlights the most significant data gaps in terms of organisms that should be examined for each water source as well as relevant water quality and environmental conditions that have been understudied to date. In general, there remain significant gaps in the literature on the 
persistence of pathogens in water matrices, particularly for protozoa. The review did not recover any persistence data on Giardia in water matrices and only a few of papers on the persistence of Cryptosporidium. Additionally, there is a significant lack of data from developing regions of the world. Most of the literature recovered in this review originated from more developed regions of the world. Consequently, the persistence of relevant microorganisms in developing country contexts such as Vibrio cholera, rotavirus and helminths have been largely unexplored. The present review recovered no data on the survival of helminths in environmental waters.

Table 17. Significant data gaps in our knowledge on the persistence of organisms in environmental matrices

\begin{tabular}{|c|c|c|c|c|c|}
\hline \multirow[b]{2}{*}{ Water Matrices } & \multicolumn{5}{|c|}{ Significant Data Gaps } \\
\hline & Bacteria & Protozoa & Viruses & $\begin{array}{l}\text { Water } \\
\text { Quality }\end{array}$ & $\begin{array}{l}\text { Environmental } \\
\text { Conditions }\end{array}$ \\
\hline Groundwater & $\begin{array}{c}\text { Campylobacter } \\
\text { Enterotoxigenic E.coli } \\
\text { Vibrio cholera }\end{array}$ & $\begin{array}{c}\text { Giardia, } \\
\text { Cryptosporidium }\end{array}$ & enterovirus & $\begin{array}{c}\text { DO } \\
\text { DOC } \\
\text { Nutrients }\end{array}$ & NR \\
\hline Surface water & NR & $\begin{array}{c}\text { Giardia, } \\
\text { Cryptosporidium }\end{array}$ & $\begin{array}{c}\text { enterovirus } \\
\text { hepatitis A } \\
\text { norovirus } \\
\text { rotavirus }\end{array}$ & $\begin{array}{c}\text { DO } \\
\text { DOC } \\
\text { Turbidity } \\
\text { Nutrients }\end{array}$ & NR \\
\hline Saltwater & $\begin{array}{c}\text { Campylobacter } \\
\text { Enterotoxigenic E.coli } \\
\text { Vibrio cholera }\end{array}$ & $\begin{array}{c}\text { Giardia, } \\
\text { Cryptosporidium }\end{array}$ & $\begin{array}{l}\text { hepatitis A } \\
\text { rotavirus }\end{array}$ & Salinity & $\begin{array}{c}\text { Cold }\left(<8^{\circ} \mathrm{C}\right) \\
\text { Warm }\left(>20^{\circ} \mathrm{C}\right)\end{array}$ \\
\hline Wastewater & $\begin{array}{c}\text { Campylobacter } \\
\text { Salmonella } \\
\text { Enterotoxigenic E.coli } \\
\text { Vibrio cholera }\end{array}$ & $\begin{array}{c}\text { Giardia, } \\
\text { Cryptosporidium }\end{array}$ & $\begin{array}{c}\text { enterovirus } \\
\text { hepatitis A } \\
\text { norovirus } \\
\text { rotavirus }\end{array}$ & $\begin{array}{l}\text { Lagoons } \\
\text { Turbidity }\end{array}$ & $\begin{array}{c}\text { Cold }\left(<5^{\circ} \mathrm{C}\right) \\
\text { Warm }\left(>20^{\circ} \mathrm{C}\right) \\
\text { Sunlight }\end{array}$ \\
\hline
\end{tabular}

NR: Not Reported 


\section{References}

Ahmed, W., Gyawali, P., Sidhu, J.P.S. and Toze, S. (2014). Relative inactivation of faecal indicator bacteria and sewage markers in freshwater and seawater microcosms. Letters in Applied Microbiology. 59, pp. 348-354. doi: 10.1111/lam.12285.

Arthur, S.E. and Gibson, K.E. (2015). Environmental persistence of Tulane virus - a surrogate for human norovirus. Canadian Journal of Microbiology. pp. 1-6. doi: 10.1139/cjm-2015-0756.

Avery, L.M., Williams, A.P., Killham, K. and Jones, D.L. (2008). Survival of Escherichia coli O157:H7 in waters from lakes, rivers, puddles and animal-drinking troughs. Science of The Total Environment. 389, pp. 378-385. doi: 10.1016/j.scitotenv.2007.08.049.

Bae, J. and Schwab, K.J. (2008). Evaluation of Murine Norovirus, Feline Calicivirus, Poliovirus, and MS2 as Surrogates for Human Norovirus in a Model of Viral Persistence in Surface Water and Groundwater. Applied and Environmental Microbiology. 74, pp. 477-484. doi: 10.1128/AEM.02095-06.

Balleste, E. and Blanch, A.R. (2010). Persistence of Bacteroides Species Populations in a River as Measured by Molecular and Culture Techniques. Applied and Environmental Microbiology. 76, pp. 7608-7616. doi: 10.1128/AEM.00883-10.

Boehm, A.B., Soetjipto, C. and Wang, D. (2012). Solar inactivation of four ItextitSalmonella serovars in fresh and marine waters. Journal of Water and Health. 10, pp. 504. doi: 10.2166/wh.2012.084.

Brooks, Y., Aslan, A., Tamrakar, S., Murali, B., Mitchell, J. and Rose, J.B. (2015). Analysis of the persistence of enteric markers in sewage polluted water on a solid matrix and in liquid suspension. Water Research. 76, pp. 201-212. doi: 10.1016/j.watres.2015.02.039.

Brown, K.I. and Boehm, A.B. (2015). Comparative decay of Catellicoccus marimmalium and enterococci in beach sand and seawater. Water Research. 83, pp. 377-384. doi: 10.1016/j.watres.2015.06.055.

Carratalà, A., Rusiñol, M., Rodriguez-Manzano, J., Guerrero-Latorre, L., Sommer, R. and Girones, R. (2013). Environmental effectors on the inactivation of human adenoviruses in water. Food and Environmental Virology. 5, pp. 203-214.

Chandran, A., Suson, P.S., Thomas, A.P., Hatha, M. and Mazumder, A. (2013). Survival of multi-drug resistant enteropathogenic ItextitEscherichia coli and ItextitSalmonella paratyphi in Vembanadu lake as a function of saltwater barrier along southwest coast of India. Journal of Water and Health. 11, pp. 324. doi: 10.2166/wh.2013.221.

Charles, K.J., Shore, J., Sellwood, J., Laverick, M., Hart, A. and Pedley, S. (2009). Assessment of the stability of human viruses and coliphage in groundwater by PCR and infectivity methods. Journal of Applied Microbiology. 106, pp. 1827-1837. doi: 10.1111/j.1365-2672.2009.04150.x.

Cook, K.L. and Bolster, C.H. (2007). Survival of Campylobacter jejuni and Escherichia coli in groundwater during prolonged starvation at low temperatures. Journal of Applied Microbiology. 103, pp. 573-583. doi: 10.1111/j.1365-2672.2006.03285.x.

Dick, L.K., Stelzer, E.A., Bertke, E.E., Fong, D.L. and Stoeckel, D.M. (2010). Relative Decay of Bacteroidales Microbial Source Tracking Markers and Cultivated Escherichia coli in Freshwater Microcosms. Applied and Environmental Microbiology. 76, pp. 3255-3262. doi: 10.1128/AEM.02636-09.

Enriquez-Enriquez, C. (1994). Detection and survival of selected viruses in water.

Flannery, J., Rajko-Nenow, P., Keaveney, S., O'Flaherty, V. and Dore, W. (2013). Simulated sunlight inactivation of norovirus and FRNA bacteriophage in seawater. Journal of Applied Microbiology. 115, pp. 915-922. doi: 10.1111/jam.12279.

Freeman, M.C., Chard, A.N., Nikolay, B., Garn, J.V., Okoyo, C., Kihara, J. et al. (2015). Associations between school- and 
household-level water, sanitation and hygiene conditions and soil-transmitted helminth infection among Kenyan school children. Parasites and Vectors. 8, pp. 412. doi: 10.1186/s13071-015-1024-x.

Fujioka, R.S., Hashimoto, H.H., Siwak, E.B. and Young, R.H. (1981). Effect of sunlight on survival of indicator bacteria in seawater. Applied and Environmental Microbiology. 41, pp. 690-696.

Gordon, C. and Toze, S. (2003). Influence of groundwater characteristics on the survival of enteric viruses. J Appl Microbiol. 95, pp. 536-44.

Gordon, C. and Toze, S. (2003). Influence of groundwater characteristics on the survival of enteric viruses. Journal of Applied Microbiology. 95, pp. 536-544. doi: 10.1046/j.1365-2672.2003.02010.x.

Ives, R.L., Kamarainen, A.M., John, D.E. and Rose, J.B. (2007). Use of Cell Culture To Assess Cryptosporidium parvum Survival Rates in Natural Groundwaters and Surface Waters. Applied and Environmental Microbiology. 73, pp. 5968-5970. doi: 10.1128/AEM.00347-07.

Jeanneau, L., Solecki, O., Wéry, N., Jardé, E., Gourmelon, M., Communal, P.-.Y. et al. (2012). Relative Decay of Fecal Indicator Bacteria and Human-Associated Markers: A Microcosm Study Simulating Wastewater Input into Seawater and Freshwater. Environmental Science and Technology. 46, pp. 2375-2382. doi: 10.1021/es203019y.

John, D.E. and Rose, J.B. (2005). Review of factors affecting microbial survival in groundwater. Environmental Science and Technology. 1, pp. 7345-7356.

John, D.E. and Rose, J.B. (2005). Review of Factors Affecting Microbial Survival in Groundwater. Environmental Science and Technology. 39, pp. 7345-7356. doi: 10.1021/es047995w.

Kay, D., Stapleton, C.M., Wyer, M.D., McDonald, A.T., Crowther, J., Paul, N. et al. (2005). Decay of intestinal enterococci concentrations in high-energy estuarine and coastal waters: towards real-time T90 values for modelling faecal indicators in recreational waters. Water Research. 39, pp. 655-667. doi: 10.1016/j.watres.2004.11.014.

Korajkic, A., McMinn, B.R., Shanks, O.C., Sivaganesan, M., Fout, G.S. and Ashnbolt, N.J. (2014). Biotic interactions and sunlight affect persistence of fecal indicator bacteria and microbial source tracking genetic markers in the upper Mississippi river. Applied and Environmental Microbiology. 80(13), pp. 3952-3961.

Korajkic, A., McMinn, B.R., Shanks, O.C., Sivaganesan, M., Fout, G.S. and Ashbolt, N.J. (2014). Biotic Interactions and Sunlight Affect Persistence of Fecal Indicator Bacteria and Microbial Source Tracking Genetic Markers in the Upper Mississippi River. Applied and Environmental Microbiology. 80, pp. 3952-3961. doi: 10.1128/AEM.00388-14.

Liang, Z., He, Z., Zhou, X., Powell, C.A., Yang, Y., Roberts, M.G. et al. (2012). High diversity and differential persistence of fecal Bacteroidales population spiked into freshwater microcosm. Water Research. 46, pp. 247-257. doi: 10.1016/j.watres.2011.11.004.

Long, S.C. and Sobsey, M.D. (2004). A comparison of the survival of F+ RNA and F+ DNA coliphages in lake water microcosms. Journal of Water and Health. 2, pp. 15-22.

Lopman, B., Gastañaduy, P., Park, G.W., Hall, A.J., Parashar, U.D. and Vinjé, J. (2012). Environmental transmission of norovirus gastroenteritis. Current Opinion in Virology. 2, pp. 96-102. doi: 10.1016/j.coviro.2011.11.005.

Lothigius, å., Sjöling, å., Svennerholm, A.M. and Bölin, I. (2010). Survival and gene expression of enterotoxigenic ItextitEscherichia coli during long-term incubation in sea water and freshwater. Journal of Applied Microbiology. 108, pp. 1441-1449. doi: 10.1111/j.1365-2672.2009.04548.x.

Marti, R., Mieszkin, S., Solecki, O., Pourcher, A.M., Hervio-Heath, D. and Gourmelon, M. (2011). Effect of oxygen and temperature on the dynamic of the dominant bacterial populations of pig manure and on the persistence of pig-associated genetic markers, assessed in river water microcosms: Pig-associated markers in river water. Journal of Applied Microbiology. 111, pp. 1159-1175. doi: 10.1111/j.1365-2672.2011.05131.x.

Mayer, R.E., Vierheilig, J., Egle, L., Reischer, G.H., Saracevic, E., Mach, R.L. et al. (2015). Automated Sampling Procedures 
Supported by High Persistence of Bacterial Fecal Indicators and Bacteroidetes Genetic Microbial Source Tracking Markers in Municipal Wastewater during Short-Term Storage at $5^{\circ} \mathrm{C}$. Applied and Environmental Microbiology. 81, (Schaffner, D.W., ed.). pp. 5134-5143. doi: 10.1128/AEM.00998-15.

Meng, Z., Chandrasena, G., Henry, R., Deletic, A. and McCarthy, D.T. (2016). Survival of E. coli and Campylobacter in surface flow constructed stormwater wetlands. Industry Report. Monash University. Australia.

Morita, S., Namikoshi, A., Hirata, T., Oguma, K., Katayama, H., Ohgaki, S. et al. (2002). Efficacy of UV Irradiation in Inactivating Cryptosporidiumparvum Oocysts. Applied and Environmental Microbiology. 68, pp. 5387-5393. doi: 10.1128/AEM.68.11.5387-5393.2002.

Ogorzaly, L., Bertrand, I., Paris, M., Maul, A. and Gantzer, C. (2010). Occurrence, Survival, and Persistence of Human Adenoviruses and F-Specific RNA Phages in Raw Groundwater. Applied and Environmental Microbiology. 76, pp. 8019-8025. doi: 10.1128/AEM.00917-10.

Ogorzaly, L., Bertrand, I., Paris, M., Maul, A. and Gantzer, C. (2010). Occurrence, survival, and persistence of human adenoviruses and F-specific RNA phages in raw groundwater. Applied and Environmental Microbiology. 76, pp. 8019-25.

Rigotto, C., Hanley, K., Rochelle, P.A., De Leon, R., Barardi, C.R. and Yates, M.V. (2011). Survival of adenovirus types 2 and 41 in surface and ground waters measured by a plaque assay. Environmental Science and Technology. 45, pp. 4145-50. doi: 10.1021/es103922r.

Rigotto, C., Hanley, K., Rochelle, P.A., De Leon, R., Barardi, C.R. and Yates, M.V. (2011). Survival of Adenovirus Types 2 and 41 in Surface and Ground Waters Measured by a Plaque Assay. Environmental Science and Technology. 45, pp. 4145-4150. doi: 10.1021/es103922r.

Rodríguez, S. and Araujo, R. (2012). Effect of environmental parameters on the inactivation of the waterborne pathogen ItextitCampylobacter in a Mediterranean river. Journal of Water and Health. 10, pp. 100. doi: 10.2166/wh.2011.044.

Schang, C., Lintern, A., Cook, P.L.M., Osborne, C., McKinley, A., Schmidt, J. et al. (2016). Presence and survival of culturable Campylobacter spp. and Escherichia coli in a temperate urban estuary. Science of The Total Environment. 569-570, pp. 1201-1211. doi: 10.1016/j.scitotenv.2016.06.195.

Seitz, S.R., Leon, J.S., Schwab, K.J., Lyon, G.M., Dowd, M., McDaniels, M. et al. (2011). Norovirus Infectivity in Humans and Persistence in Water. Applied and Environmental Microbiology. 77, pp. 6884-6888. doi: 10.1128/AEM.05806-11.

Seitz, S.R., Leon, J.S., Schwab, K.J., Lyon, M.G., Dowd, M., McDaniels, M. et al. (2011). Norovirus infectivity in humans and persistence in water. Applied and Environmental Microbiology. 77, pp. 6884-6888. doi: 10.1128/AEM.05806-11.

Sidhu, J.P.S., Toze, S., Hodgers, L., Barry, K., Page, D., Li, Y. et al. (2015). Pathogen Decay during Managed Aquifer Recharge at Four Sites with Different Geochemical Characteristics and Recharge Water Sources. Journal of Environment Quality. 44, pp. 1402. doi: 10.2134/jeq2015.03.0118.

Sidhu, J.P.S. and Toze, S. (2012). Assessment of pathogen survival potential during managed aquifer recharge with diffusion chambers. Journal of Applied Microbiology. 113, pp. 693-700. doi: 10.1111/j.1365-2672.2012.05360.x.

Skraber, S., Ogorzaly, L., Helmi, K., Maul, A., Hoffmann, L., Cauchie, H.M. et al. (2009). Occurrence and persistence of enteroviruses, noroviruses and F-specific RNA phages in natural wastewater biofilms. Water Res. 43, pp. 4780-9. doi: 10.1016/j.watres.2009.05.020.

Skraber, S., Ogorzaly, L., Helmi, K., Maul, A., Hoffmann, L., Cauchie, H.M. et al. (2009). Occurrence and persistence of enteroviruses, noroviruses and F-specific RNA phages in natural wastewater biofilms. Water Research. 43, pp. 4780-4789. doi: 10.1016/j.watres.2009.05.020.

Smith, J.J., Howington, J.P. and McFeters, G.A. (1994). Survival, physiological response and recovery of enteric bacteria exposed to a polar marine environment. Appl. Envir. Microbiol. 60, pp. 2977-2984.

Smith, J.J., Howington, J.P. and McFETERS, G.O.R.D.O.N.A. (1994). Survival, physiological response and recovery of 
enteric bacteria exposed to a polar marine environment. Applied and Environmental Microbiology. 60, pp. 2977-2984.

Walters, S.P., Yamahara, K.M. and Boehm, A.B. (2009). Persistence of nucleic acid markers of health-relevant organisms in seawater microcosms: Implications for their use in assessing risk in recreational waters. Water Research. 43, pp. 4929-4939. doi: 10.1016/j.watres.2009.05.047.

Yates, M.V., Gerba, C.P. and Kelley, L.M. (1985). Virus persistence in groundwater. Applied and Environmental Microbiology. 49, pp. 778-781.

J. Yeager, G.A.R.Y. and Ward, R.L. (1981). Effects of moisture content on long-term survival and regrowth of bacteria in wastewater sludge. Applied and Environmental Microbiology. 41, pp. 1117-1122.

Zhang, Q., He, X. and Yan, T. (2015). Differential Decay of Wastewater Bacteria and Change of Microbial Communities in Beach Sand and Seawater Microcosms. Environmental Science and Technology. 49, pp. 8531-8540. doi: 10.1021/acs.est.5b01879. 